\title{
Application of Tuned Mass Dampers for Structural Vibration Control: A State-of-the-art Review
}

\author{
Fatemeh Rahimi ${ }^{\text {a,b* }}$, Reza Aghayari ${ }^{\text {b }}$, Bijan Samali ${ }^{\text {a }}$ \\ ${ }^{a}$ Centre for Infrastructure Engineering, Western Sydney university, NSW, Australia. \\ ${ }^{b}$ Department of Civil Engineering, Razi University, Kermanshah, Iran.
}

Received 01 April 2020; Accepted 28 June 2020

\begin{abstract}
Given the burgeoning demand for construction of structures and high-rise buildings, controlling the structural vibrations under earthquake and other external dynamic forces seems more important than ever. Vibration control devices can be classified into passive, active and hybrid control systems. The technologies commonly adopted to control vibration, reduce damage, and generally improve the structural performance, include, but not limited to, damping, vibration isolation, control of excitation forces, vibration absorber. Tuned Mass Dampers (TMDs) have become a popular tool for protecting structures from unpredictable vibrations because of their relatively simple principles, their relatively easy performance optimization as shown in numerous recent successful applications. This paper presents a critical review of active, passive, semi-active and hybrid control systems of TMD used for preserving structures against forces induced by earthquake or wind, and provides a comparison of their efficiency, and comparative advantages and disadvantages. Despite the importance and recent advancement in this field, previous review studies have only focused on either passive or active TMDs. Hence this review covers the theoretical background of all types of TMDs and discusses the structural, analytical, practical differences and the economic aspects of their application in structural control. Moreover, this study identifies and highlights a range of knowledge gaps in the existing studies within this area of research. Among these research gaps, we identified that the current practices in determining the principle natural frequency of TMDs needs improvement. Furthermore, there is an increasing need for more complex methods of analysis for both TMD and structures that consider their nonlinear behavior as this can significantly improve the prediction of structural response and in turn, the optimization of TMDs.
\end{abstract}

Keywords: Vibration Control; Tuned Mass Damper; Structural Response; Natural Frequency Tuning.

\section{Introduction}

The speedy growth of urbanization resulted in a historic increase in the number of structures and high-rise buildings. Excessive vibration in high-rise buildings expected to be induced by external forces such as earthquake and wind [1]. The induced vibration may lead to structural damage and unsatisfactory performance of structures. Induced vibration can cause significant inconvenience if not casualties. Therefore, to enhance the safety and functionality of the structure, vibration control of the structural systems has long been considered by structural designers which serve as major technological competitiveness [2]. Some technologies developed and adopted to control excessive vibration and to mitigate its impact on the structural response and keep it within the sustainable limits during unpredictable events such as earthquakes.

\footnotetext{
* Corresponding author: fatemehrahimi77@gmail.com
} 
Many vibration control technologies have been adopted to decrease the damage and amend the structural performance, including damping, vibration isolation, control of excitation forces, vibration absorber. Each system has its own limitations and advantages and the choice of a particular control system is usually decided by consideration of a number of factors such as effectiveness, convenience, life cycle cost. Among vibration absorbers, Tuned Mass Damper (TMD), Active Mass Damper (AMD), Semi-active mass damper (SAMD) and Hybrid Mass Damper (HBD) have been studied and installed in high-rise buildings to control their behavior under excitations [3].

Among various structural control techniques Tuned Mass Damper (TMD) is a popular option because of its simple principle and easier execution on existing buildings with comparatively modest change. The adequate option of damper parameters required for the structural system to act efficiently. Different from the formal vibration mitigation techniques, which rely on the strength, stiffness, and ductility of the structures, vibration control is a collection of technical, in earthquake engineering, in order to decrease the seismic impacts and response in structural buildings and non-structural ingredients through the installation of different control devices in the structures.

An Active Mass Damper (AMD) consisting of an AC servo motor, a movable mass connected to the AC servo motor by a ball-screw a mechanism, and an accelerometer as a sensor for measurement was considered [4]. Also, AMD control system regulates the dynamic energy by distributing it between the inner mass and the structure, through catering a pair of control force between them. SAMD does not inject any mechanical energy into the controlled structure, but instead, its properties can be controlled (i.e. adjustable stiffness or variable damping devices or both) to optimally mitigate the response of the system [5]. As such, SAMD systems need smaller magnitude of energy from external power source compared with AMD systems. SAMD systems, therefore, has a vibration-reducing effect similar to that of AMDs, while on the other hand, SAMDs do not have the issue associated with energy input into the primary structure as in AMDs. Due to the advantages of semi-active control systems over active and passive control systems, significant research effort has been put into this field and many of the semi-active control devices have been developed and tested [5]. Therefore, innovative systems, such as hybrid control systems have become more attractive options.

The performance of TMD and its successful application in vibration control systems depend on several factors, the most important of which are shown in Figure 1. In order to ensure that the dynamic response of structure is successfully controlled with TMDs, these factors need to be taken into account when designing and implementing them in a structure. Modal parameters of both the structure and the damper can significantly affect the structural response and therefore TMDs need to have certain modal characteristics, otherwise it may even have adverse effects. While it is well established that the higher mass ratio improves the performance of TMDs, it is usually limited by the technical and economical feasibility. Once TMD is installed, a control algorithm is needed to adjust its operating characteristics to the external forces and its proper design and implementation can play an important role on the overall performance of the TMD and the control system. Selecting a proper location (or locations in MTMDs) is also an important factor in controlling the structural response. The frequency to which the TMD is tuned to, is one of the most important factors in TMD design.

The Soil-Structure Interaction (SSI) is also known to impact the performance of the TMD in controlling vibrations and studies have shown that neglecting leads to an overestimation of TMD performance. This paper is an attempt to provide an up-to-date review of the current knowledge on TMDs in structural vibration control and recent advancements of the field, based on which a series of recommendations for future works are highlighted. In order to achieve this, the background and theoretical aspects of vibration control systems, and how they can improve the structural response to external dynamic forces have been presented in section 2. Then, a brief description of TMDs and their types are provided, and their application and performance using different vibration control systems with different control algorithms are discussed in section 3. Section 4 discusses different numerical approaches and their applications in structural response prediction when TMDs have been implemented. Experimental studies have also been surveyed in section 6 where different types of TMDs have been implemented in control systems. We have also investigated different studies concerned with TMD optimization and compared the advantages and advantages of different optimization techniques in section 7. Section 8 is dedicated to the role of soil -structure interactions in the efficiency of TMDs, while section 9 provides a summary of application of TMDs in bridges, as an important civil infrastructure, over the last few decades. 


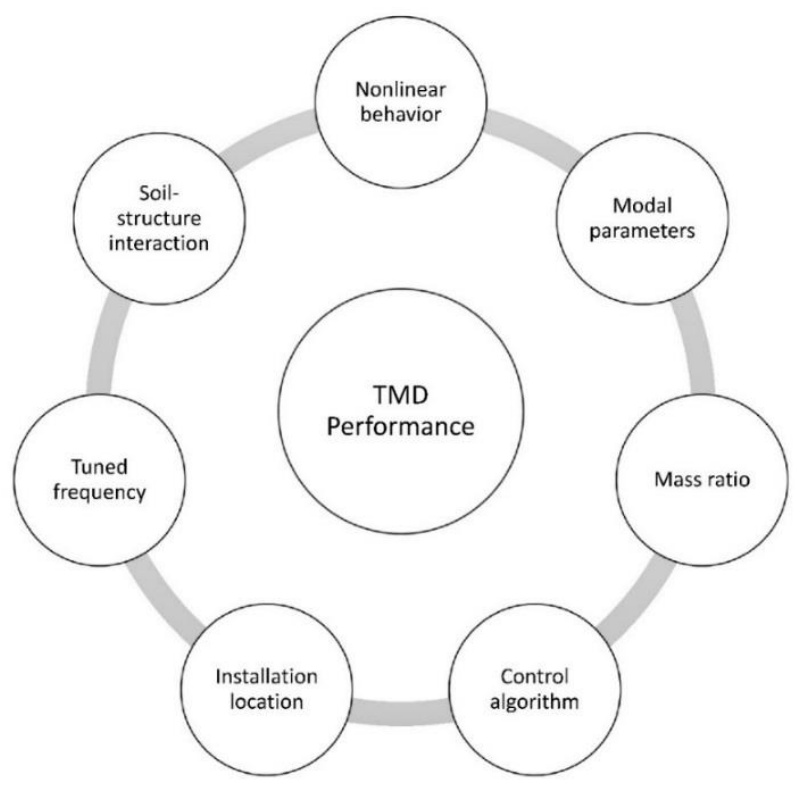

Figure 1. Factors affecting the performance of TMDs

\section{Vibration Control of Structures}

Structural control is another way to guarantee structural safety and to keep vibration within sustainable limits in addition to the formal design methods. A number of recent researches are available to control the induced vibration of the structural system. Researchers have extended the structural control systems which can keep structures and modify their efficiency during seismic events. Passive or active stabilizing forces can be used on the structure using external dampening devices to mitigate the effect of structural vibrations [6]. Passive control of structures, which does not need an external power source, reduces structural vibrations through dissipating the kinetic energy-filled in structures without the need for an external power source. Universally, the structural kinetic energy can decompose either by conversion to heat or by transmitting through vibrating modes. This control system includes supplemental damping apparatus such as tuned mass dampers, tuned liquid dampers, and base isolations. These methods are well-realized and are widely admitted by the engineering community as a means for mitigating the effects of dynamic loading on structures. However, these passive-device methods are incapable to adjust to structural modifies and to varying usage samples and loading conditions [7]. A number of researches decided to develop different structural control systems to diminish structural responses under seismic excitation and wind load. Still numerous research works are going on to develop the effectiveness of these systems. Vibration control techniques can broadly arrange into four major groups based on their operational mechanism [8-10]. At the end of this part three vibration control systems such as Passive, Semi-active and full active control of structures show as Figure 2.

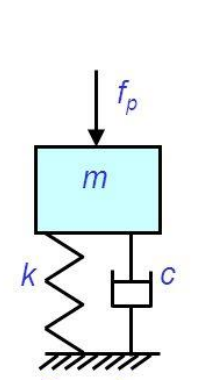

Passive

\section{Active Vibration Control}
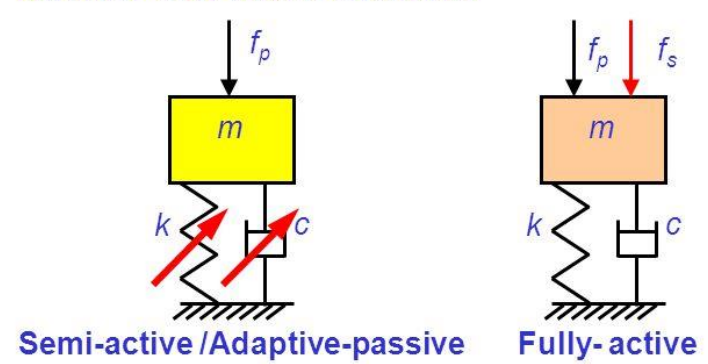

-Passive - Mass, stiffness and damping (quantity and distribution) fixed at the design stage

- Semi-active I - Stiffness and/or damping properties changed to adjust Adaptive-passive internal dynamic forces to minimise the response

- Fully-active - Dynamic forces applied to the system to minimise the response

Figure 2. Passive, Semi-active and full active control of structures [11] 


\subsection{Passive Control Systems}

Passive control systems are the most common among structural control devices. Passive systems work by dissipating the vibrating energy. This group is consisting of mainly seismic isolation and energy dissipation devices. This system considers as smart system in the past since they can create a higher damping force when the structural response becomes higher [8]. Usually, passive control systems do well, only for particular dynamic loading for which they designed and tuned. As such, passive control systems considered as systems with limited control capacity which are not capable of adapting to different types of excitation. Despite, these limitations, their advantages are the lack of need for any external energy source to act during excitation, and their simple design and construction.

\subsection{Semi-Active Control Systems}

Semi-active control devices are an advanced form of passive devices with adaptive capacity, where the damper behavior is controlled based on the collected information on the excitation and response of the structure. These systems consist of sensors, control computer, control actuators and a passive damping device, along with a small power source to. It should note that the semi-active system does not have full control capacity since they are limited within the range of the capacity of installed passive devices [12].

\subsection{Active Control Systems}

Active control systems have been developed to enhance the capabilities of passive and semi-active systems in seismic structural response control [9]. They develop active systems to tolerate the unpredictable vibrations induced by various excitations. However, system setup and its components are complicated and a relatively large amount of external energy is required for an active system to function during natural hazard event such as earthquakes [10]. Moreover, the active system will become inoperative if the external power supply fails during natural hazard events. Active mass damper systems, active base isolation systems, and active bracing systems are examples of active control devices.

\subsection{Hybrid Control Systems}

Hybrid control systems are the combination of passive, active and semi-active devices connected into series or parallel. These systems became a promising solution because they have the advantage of passive, active and semiactive control systems. Passive part works to decrease the structural response and keeps the performance of the structure within the desirable limit. Active part is applied to tune and adjust the response. Hybrid control systems are effective to protect structures subjected to different types of excitation with dissimilar intensity and frequency range [13]. Hybrid control systems, as the name suggests, use the combined of active and passive control systems. Examples of such systems include a structure equipped with distributed viscoelastic dampers and an active tuned mass damper on or near the top floor; or a base-isolated structure with actuators that are actively controlled to enhance performance [14]. Since both active and passive controlling devices adopt, hybrid systems have the benefits of both techniques while the limitations of either of the techniques alone are mostly diminished.

\subsection{Smart Structures}

A smart structure is an intelligent machine which can figure out its dynamic loading environment through sensors and can modify and adapt to its environment, dynamically in real-time, so that it can sustain external dynamic forces, such as earthquake loading, wind or impact. In a smart structure, designed an anticipated number of members to be actively controlled members. Each member has a sensor, a feedback control device and an actuator [4]. The sensor stacks up the displacements along the degrees of freedom. Then the feedback control device specifies the proper correction to the uncontrolled response, and the actuator exerts the required force.

\section{Tuned Mass Damper}

A passive TMD includes a secondary mass with properly tuned spring and damping elements such that the dynamic specifications of the structure change and a frequency-dependent hysteresis is enabled to grow to damp in the structure. It has been well appointed that TMD is impressive in diminishing the wind-excited structural vibrations [15]. TMDs have fixed frequency and damping characteristics and can use to tune only a given fixed frequency of vibration, normally the fundamental frequency of vibrations of a structure. TMDs have been vastly used to underestimate mechanically induced vibration [16]. The device mounted in the structure to mitigate the dynamic response. TMDs have constant frequency and damping characteristics and can operate to tune only a given constant frequency of vibration, normally the main frequency of shakes of a structure.

TMD systems were expanded as an innovative system for passive vibration control of building structures in the 1970s [17]. Since then, they have been installed in a number of high-rise buildings [18]. TMDs can effective when the 
original frequency of the structure governs the response, which may be the case for vibrations under common winds. TMD systems are not as impressible for uncommon structures under strong ground motion, when several different modes of vibration may contribute considerably to the dynamic the response of the structure. Due to the fact that TMD must tune only with the structural main mode, it may not have any advantage in protection against some earthquakes such as Kobe, which motivates other modes instead of that utilized to tune TMD. On the other hand, this shortcoming has been overcome with the emergence of multiple tuned mass dampers (MTMDs) [19].

The initial notion of tuned mass damper followed back to 1909 when Farham create a dynamic vibration absorber to control the vibration [16]. Since then, researchers have done a lot of work in the passive control theory and application. In early 1950s, the engineers in previous Soviet Union performed impulsive pendulum on the steel tower and chimney to mitigate the structural vibration under wind load motivation. In 1970s, engineers installed hundreds of tons of TMD on the $343.5 \mathrm{~m}$ high John Hancock Tower in Boston and the 292.6m high Citicorp Center in New York City, and effectively diminished the wind-induced vibration [20]. In 1980, a TMD was also successfully mounted on the Sydney Tower to control the wind-induced vibration in Australia and in Japan, the first TMD device was installed on the Chiba Port Tower in 1980, and followed by the Fund Bridge in Osaka [21]. In 2004, 660 tons of sphere liked TMD was installed on the Taipei 101 Tower in Taiwan, which is the biggest damper in the world [22].

Ahsan et al. [23] facilitated the design of TMD to control a single model of an MDOF system. In addition, they also tested the outlook of controlling multiple structural modes with multi-tuned mass dampers (MTMD). Other studies investigated 19 distinguish optimal parameters of MTMDs to reduce dynamic response of structural system, by Yau and Yang [24], Lee et al. [25], Li and Qu [26]. Chang [27] studied and compared the efficiency of TMD, tuned liquid column damper (TLCD) and liquid column vibration absorber (LCVA). He also fixed total building mass damper equations by considering the building as SDOF system and taken some optimum design formulas in closed forms for both wind and earthquake. Lin et al. [28] applied an extended accidental diminution method to reduce dynamic responses of a PTMD system against to seismic load. Lee et al. [25] proposed an optimal design theory for buildings associated with TMDs at different story level and power spectral density (PSD) function of environmental disturbances. Optimal design parameters declared in terms of damping coefficients and spring constants through minimization of structural responses. A numerical algorithm was also developed to search optimal design parameters of MTMDs. Bakre and Jangid [29] developed explicit mathematical statements for optimum TMD parameters using numerical searching technique. [30] included nonlinear viscous damping elements to TMD and analyzed the effect. Unlike previous studies related to TMD optimization where TMD mass ratio was a predefined parameter, Sgobba and Marano [31] optimized TMD mass ratio before with other parameters.
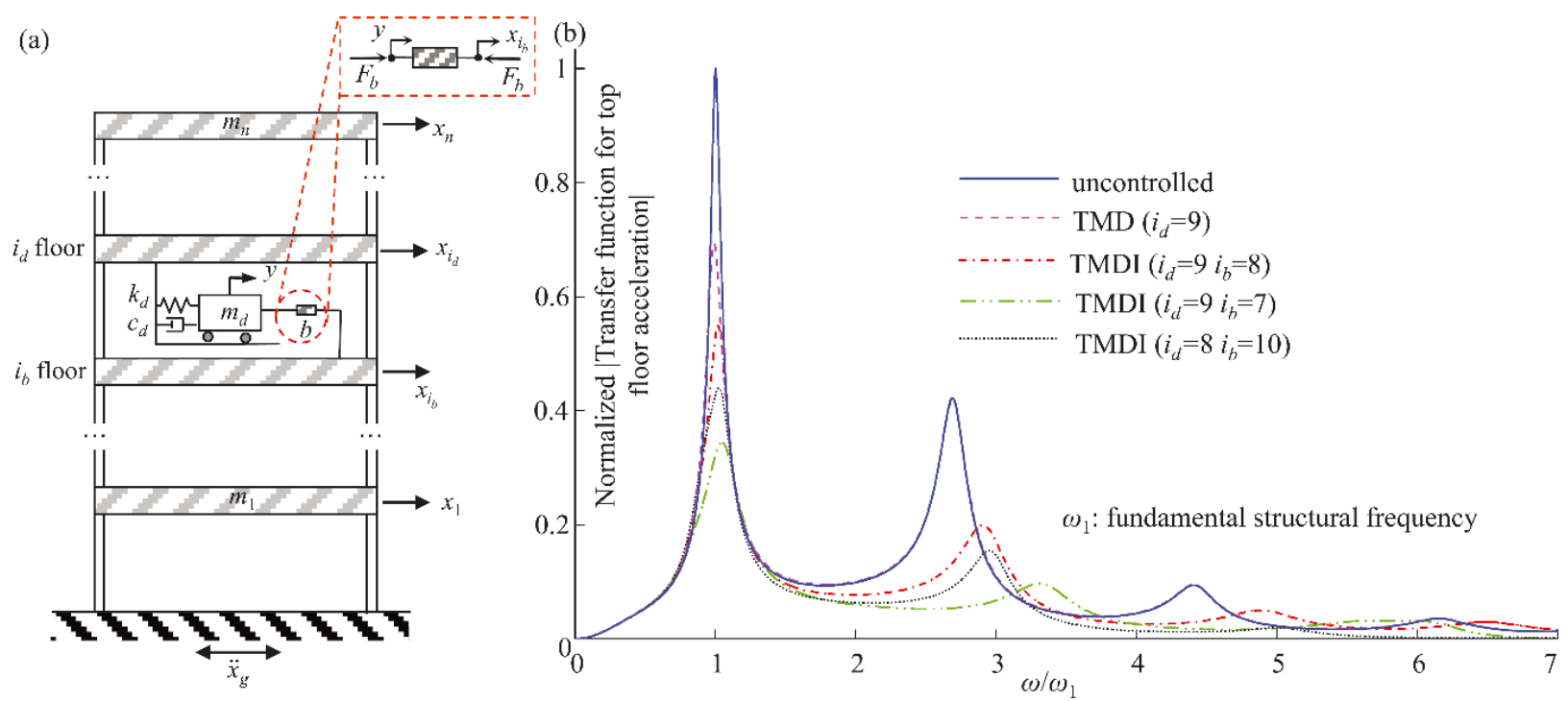

Figure 3. (a) Tuned mass-damper-inerter (TMDI) equipped multi-storey frame structure and ideal inerter device with inertance b under equilibrium with an external force $F$ (inlet); (b) Normalized absolute frequency response functions for the top floor acceleration of the 10-storey structure [32].

\subsection{Types}

\subsubsection{Single TMD}

Single TMD composes of a mass, spring and a damper. The mechanism of suppressing structural vibration by TMD use to transfer the vibration energy of the structure to the TMD and dissipate energy (Figure 4a). It is necessary to tune the natural frequency of the TMD to structural motion and choose the fit capacity of the damper. The concept of applying one TMD (STMD) was emanated since the skeptical made by [9]. He tried to use a spring absorber to 
control rolling motion in ships, and undamped mass-spring absorber showed the ability to adjust the amplitude of the original system nearly to zero for a single frequency. Elias and Matsagar [16] studied the response analysis of the TMDs dependent on the structures subject to vortex loading of sinus type. They presented that the TMDs were entirely beneficial in response reduction of the structures. Inceo and Gürgöze [33] reported that the TMD was effective in reduction of bending vibrations in beams. Rasouli and Yahyai [34] showed a remarkable development in the effects of the TMD performance in controlling the structural shifts against stimulations which frequency is near to the basic frequency of the buildings. Wong and Chee [35] found that the TMD was very impressive in mitigating both the greatest kinetic energy and strain energy of the structure, while it was also effective in reducing the amount of damping energy that must dissipate through the structure. A frequency analysis of the TMD system was studied by $[36,37]$, wherein it displayed that the ancient frequency tuning causes to equal damping ratio of the two vibration modes of the Hybrid system. Hwang et al. [37] and Li and Cao [38] proposed a method for estimating the modal mass of a real structure with a TMD based on the $\mathrm{H}-\infty$ optimal model diminution technique. However, the effectiveness of a single TMD may impair significantly in real applications because of its high sensitivity to frequency detuning or to variation of the damper damping ratio. Proposed by $\mathrm{Xu}$ and Igusa [39], the use of multiple TMDs with distributed natural frequencies overs a solution to such cases. It has shown that multiple TMDs can be made more effective than a conventional optimal single TMD of the same total mass and, furthermore, performance of multiple TMDs is less sensitive to uncertainties in the parameters of the system.

The TMDs restricted to having identical masses and damping ratios, along with natural frequencies equally spaced over a frequency range. With these constraints, Yamaguchi and Harnpornchai [40] performed a parametric study on the effect of TMDs on a single degree of freedom (SDOF) structure under harmonic forces. They found that, for a given number of TMDs, there exist an optimal frequency range and an optimal TMD damping ratio which make the structural response minimum. After that, Abé and Fujino [41] analytically studied the constrained TMDs. A perturbation technique used to derive explicitly modal properties of the combined system. Accordingly, a TMD damping ratio to maximize the lowest modal damping and a critical TMD frequency range to make modal amplitudes equal derived in simple formulas. These formulas are relevant to the design of those simplified TMDs toward the minimum response. Also shown in both the above studies, the sensitivity of the multiple TMDs against uncertainty in the structural frequency can diminish significantly by widening the TMD frequency range. Igusa and Xu [42] analytically designed multiple TMDs for a SDOF structure subjected to a wide-band force. In trying to generalize the optimal design problem, they relaxed the earlier restrictions on natural frequencies and damping ratio of TMDs. An asymptotic analysis and an integral limit used to obtain a simple approximation for the mean square displacement response of the main structure. This approximate response is independent of the TMD damping ratios but these damping must lie within certain bounds for its accuracy. An analytical optimization was then conducted for the approximate response using calculus of variations. Their optimal result shows that the natural frequencies of the TMDs are unequally distributed over a frequency range centered at the controlled structural frequency and the width of this frequency range is proportional to the square root of the ratio of the total TMD mass and the main mass.

\subsubsection{Multi TMD}

Igusa and $\mathrm{Xu}$ [42] proposed a new concept of multiple tuned mass damper (MTMD) for controlling structural vibration with variable frequencies. The basic idea is to use a large number of small TMDs whose natural frequencies are distributed around the dominant natural frequency of a structure to have a TMD system with more robust performance (Figure 4b). The model characteristics and efficiency of the MTMD studied by Abé and Fujino [43] using the perturbation technique. The dynamic characteristics and performance of the MTMD system under random loading were further analyzed by Kareem and Kline [44]. Recently, the MTMD system has extended to control structures with closely spaced natural frequencies [45] using the perturbation technique. Sakr [46] established the novelty of MTMDs to the alteration of partial loads of the structure at a restricted stories' level into tuned mass dampers, omitting the need of huge masses and dampers for the purpose, and reported that increasing the story :mass ratios and the number of floors used as TMDs improves the response of structures during earthquakes. Finding the appropriate location for MTMDs can distributed uniformly, linearly, and engineer's opinion. These dampers with minimize mass would offer better control during the wide range of frequency and eliminate the waste space during the installation of MTMDs. MTMDs created the uniform distribution of masses for economical reason [47]. The experimental study of these TMDs' type has done to investigate their performance in mitigating the displacement, peak of acceleration and base shear of structures along of earthquake and by optimization algorithm the best position of MTMDs identified [48].

Most existing studies have focused on the specific modes of vibration by simulating the buildings as a singledegree-of-freedom. From operational point of view, the application of big single TMD in tall buildings can change the architectural demand, as its installation within the limited space can be challenging [48]. Single TMDs tuned to the first three natural frequencies and during the excitation the frequency of the structures may be similar to the TMD's frequency and create the resonance and the structures' response approaches infinity. Meanwhile, by using Multiple 
Tuned Mass Dampers (MTMDs) the possibility of aggravation is reduced. While single TMDs are simple, more economical and more authentic tactics for structural vibration control [49], their performance depend on the optimization of tuning frequency and damping parameters. Therefore, STMDs are prone to some problems such as mistuning, off-optimum damping, and weak performance for reduction of response when structures had multimode [50]. MTMDs make a wide bandwidth compared to single TMDs and hence diminish the frequency mistuning issue by changing the structural frequency. Another advantage of MTMDs is the freedom regarding their arrangement and placement which can further enhance the structural response control capability. For instance, recent study [51-54] evaluated and showed the superior performance of MTMDs with homogenous and non- homogeneous mass distribution where the mass ratio, damping ratio, peak ground acceleration and structural periods were improved.

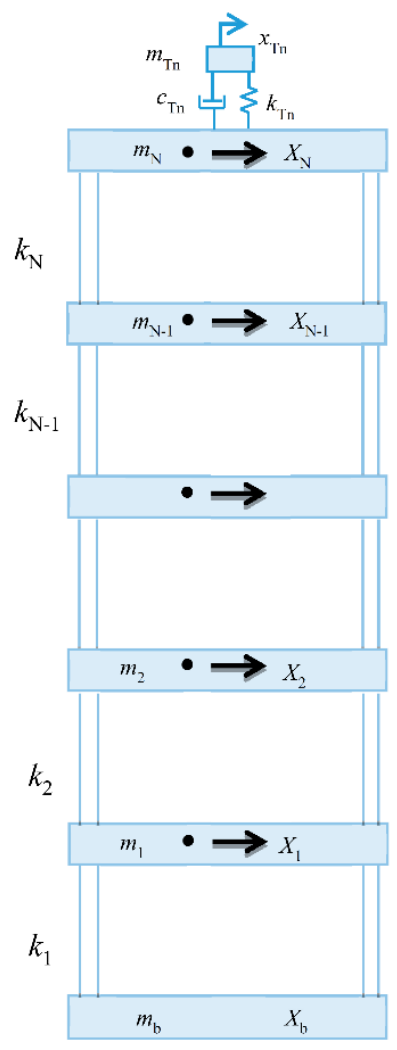

(a)

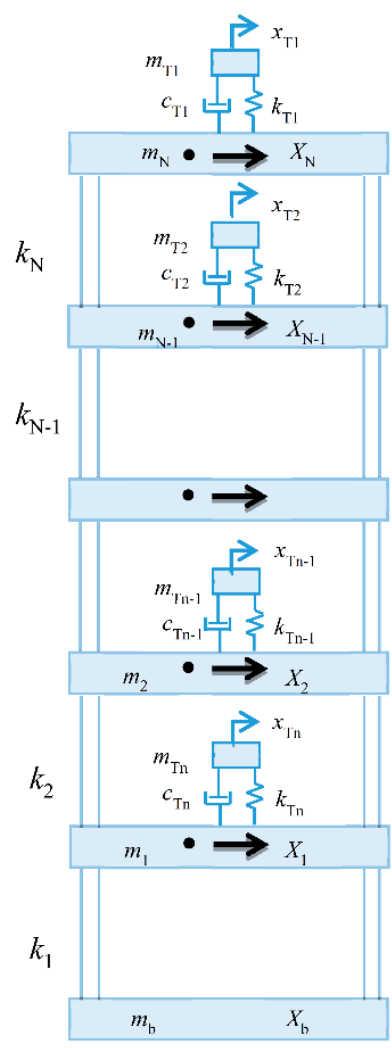

(b)

Figure 4. (a): Single TMD and, (b): Multi TMD [55]

\section{Structural Control with Different Types of TMDs}

\subsection{Passive Tuned Mass Damper}

The normal frequency of the TMD is tuned in resonance with the first mode of the building structure so that the massive structural vibrating energy is propagated to the TMD and dissipated by the dampers to protect the structure against the earthquake loads. The efficiency of dampers should be drastically mitigated if the parameters are off tuned to the vibrating mode it is designed because of inescapable presence of doubt in the system parameter. For instance, this system was used in high-rise buildings to decrease the oscillation of the building in the wind [56]. KamraniMoghaddam et al. [57] investigated the performance of TMDs in the response reduction of structures for near-field and far-field earthquakes. The 3-, 9- and 20-story structures designed for the SAC phase II project were utilized in this research. First, time-history analyses were done to compute the response of each structure to the Chi-Chi, Kocaeili and Landers near-field and far-field earthquake records. The same method was followed for the models with a TMD duly attached. The results have shown that the efficiency of TMD in the 3-story structure was better for the far-field excitations, while in the 20-story structure, the performance was better for the near-field excitations. Pinelli and Gutierrez [58] studied and compared the feasibility and effectiveness of different combinations of TMDs in controlling the seismic vibrations of a structure. These included a single TMD tuned to one mode, multiple single TMDs controlling several modes (i.e., MTMDs), a battery of TMDs controlling one mode, also known as distributed tuned mass dampers (DTMDs), and several batteries controlling different modes, also known as multiple distributed tuned mass dampers (MDTMDs). Three public benchmark case studies were subjected to earthquakes with various periods and energy contents and their performances were analyzed with different combinations of TMDs. Pinelli and Gutierrez 
[58] showed that MTMDs effectively control the structural response during earthquakes of various periods and energy contents. Their results showed that MTMD systems result in an average of $10 \%$ improvement in acceleration reduction over a single-TMD system, while similar displacement reduction is achieved.

The first building in the US to be designed with a TMD from the beginning appears to be the 70-story Park Tower in Chicago completed in 2000 [59]. Despite the emergence of nearly four-decade-old technologies in practice, as a technological marvel, TMD systems have several shortcomings. First, it is not possible to calculate the fundamental frequency of vibration of a structure accurately. Second, this frequency changes during an extreme dynamic event, such as strong ground motion. TMD systems can be partially effective when the fundamental frequency of the structure dominates the response, which may be the case for vibrations under ordinary winds. TMD systems are not as effective for irregular structures under strong ground motion, when several different modes of vibration may contribute significantly to the dynamic response of the structure. TMD has limited performance because of constant damper parameters, a confined suppression frequency range, diminution of non-stationary vibration, and a sensitivity difficulty because of detuning.

\subsubsection{Advances of Tuned Mass Damper System}

In order to overcome the restrictions of the passive TMD, the Semi-Active Tuned Mass Damper (STMD) and the Active Tuned Mass Damper (ATMD) or the Active Mass Damper (AMD) or Hybrid TMD were proposed. Both technologies use the electronic source and control board to understanding the motion of structure and to activate the control force. However, the STMD does not create a direct force but rather variations its normal frequency by changing either stiffness or damping attributes to quench vibrations [60]. This is beneficial compared with AMDs where the electrical power is not existent since it can still create existing damping or stiffness to the structure.

AMDs apply a controlled force calculated using a control algorithm and based on a sensor signal, hence resulting in active control of the vibration [61].

Table 1. Literature review of past and new generation of TMDs

\begin{tabular}{|c|c|c|}
\hline TMD & Performance of TMD & Information about the features of each system \\
\hline \multirow[b]{2}{*}{$\begin{array}{l}\text { Sadek et al. } \\
{[62]}\end{array}$} & & $\begin{array}{l}\text { 1- Determining the optimum parameters of tuned mass dampers to decrease } \\
\text { the vibration of structures against to earthquake. }\end{array}$ \\
\hline & Parameters of tuned mass dampers & $\begin{array}{l}\text { 2- Considering the mass ratio, tuning and damping ratios of the TMDs. } \\
\text { 3- TMD parameters reduce the displacement and acceleration responses } \\
\text { significantly ( } 50 \text { percent). }\end{array}$ \\
\hline
\end{tabular}

Chang and $\mathrm{Qu} \quad$ Unified dynamic absorber design formulas for

1- Unified design formulas for various passive dynamic absorbers for wind [63] wind-induced vibration control of tall buildings vibration control of tall buildings.

2- Unified equation of motion for tall buildings.

3- Achieve to optimal properties and equivalent damping ratio.

1- When damping and mass ratio is increasing, the effect of detuning in TMDs parameters becomes less detrimental

2- During time-history analysis, when damping is getting large, TMD

Rana and

Soong [64]

Parametric study and simplified design of TMD

Chang [27]

Mass dampers and their optimal designs for building vibration control performance is reducing.

3- Optimal parameter values of TMDs is used for the base and main mass excitation.

3- After using of MTMs, detuning occurs in higher modes of MTMDs and performance is decreased.

1- The control performance of three types of mass dampers (tuned mass damper (TMD), the tuned liquid column damper (TLCD) and the liquid column vibration absorber (LCVA)) on suppressing excessive building vibration is studied.

2- For a given mass ratio between the mass damper and the SDOF system, the performance of the mass damper is efficiency.

3- The control performance of the TMD is better than the liquid type of mass dampers (TLCD and LCVA).
Chen and $\mathrm{Wu}$ Optimal placement of multiple tuned mass [50] dampers for seismic structures
The optimal design and placement of multi-mode tuned mass dampers have been studied for reducing the floor acceleration of multi-storey building structures under earthquake loads.

1- By increasing the mass ratio of TMD to the building, the damping of the building increases linearly and also displacement of the structure reduces structure.

2- Changing the position of TMD to different floors, the appropriate position for adjusting the TMD is founding. 
3- If the frequency of TMDs is near the frequency of structures, using active mass dampers instead of Passive TMDs for controlling the response of structures.

Optimum properties of multiple TMDs for Li and Liu [65] reduction of the response of structures subject to ground acceleration
Bakre and Jangid [29]

Optimum multiple tuned mass dampers for the base-excited damped main system

1- The analytical expressions for the translational and torsional displacement dynamic magnification factors (DMF) and the effectiveness of the MTMD in reducing both the translational and torsional responses of asymmetric structures.

2- The frequency response curves of asymmetric structures without and with both the optimum MTMD and TMD are plotted for the three cases of TTFR, consequently obtaining some very useful results.

1- The optimum parameters of MTMD for suppressing the dynamic response of a base-excited damped main system are investigated.

2- The minimization of the steady-state displacement of the main system under harmonic base acceleration.

3- The optimized parameters: the damping ratio, the tuning frequency ratio and the frequency bandwidth.

4- The results show that the optimized MTMDs is better performance than single TMDs.

1- The vibration control effectiveness of PTMDs for reducing the seismic responses of torsional coupled buildings was investigated.

Practical design issues of tuned mass dampers

Ueng et al. for torsional coupled buildings under [66] earthquake loadings

2- The optimal location for the installation, planar position and movement direction of PTMDs were considered and parametric studies have done on PTMD planar positions and detuning effects for frequency and damping ratio.

3- The result shows that the response control for two PTMDs installed in two orthogonal directions produced a better performance than one PTMD installed in a weaker direction when both cases had the same total PTMD mass.

1- The optimal TMD has a lower tuning frequency and higher damping ratio with increasing mass ratio.

Hoang et al. Optimally tuned mass damper for seismic [67] applications and practical design formulas

2- With a large mass ratio, a TMD becomes very effective in minimizing the primary structure response while it generates a fairly small stroke length.

3- The characteristic ground frequency has a strong influence on the optimal tuning frequency than the optimal damping ratio of TMD.

4- The TMD optimally designed based on the excitation spectrum.

1- Closed-form, easy-to-use design formula for optimal performance of bituned mass dampers system using a non-dominated sorting genetic algorithm

2- The performance of the damped structural system is described by two measures; nominal and robust performance indices. The nominal index represents the effectiveness of the bi-tuned mass dampers when it is precisely tuned to the first modal frequency of the target structure.

3- The optimal tuning frequencies and damping ratios of the bi-tuned mass dampers are then expressed in terms of the total mass ratio of the bi-tuned mass dampers.

1- TMDs can be distributed vertically along with the building height without substantial loss of their effectiveness for tall-building motion control.

2- By distributing TMDs vertically with multiple small TMDs at each level, the system reliability is enhanced.

Moon [69] Vertically distributed multiple tuned mass dampers in tall buildings

3- In order to save the space used for TMD installation, TMD motion can be reduced by increasing the TMD damping ratio over its optimal value.

4- Vertically distributed MTMDs possess a high potential of practical applications for tall-building motion control.

1- The analysis results show the necessity and effectiveness of TMD systems for vibration mitigation of the SHC under wind excitation.

2- The TMD system also has an influence on suppression of the structural wind-induced displacement response.

1- Wind and earthquake effects on high-rise buildings in order to apply for designing of structures. A reduction in the worst peak acceleration is more than $20 \%$, by changing the building orientation.

Aly [71] Design of buildings for wind and earthquake

2- For the response prediction under wind loads, general agreements between the results of the pressure integration technique and the aeroelastic experiment exist.

3- The result shows that wind and earthquake loads are different from each other and are also different from static loads. 
Farghaly and Salem Ahmed [72]

Optimum Design of TMD System for Tall Buildings

An alternative methodology for designing tuned Moutinho [73] mass dampers to reduce seismic vibrations in building structures

1- Time response and shear force of structure can be dramatically reduced by using TMDs.

2- Single TMD is better used when distributed through the elevation of the model.

3- The best using of TMDs is distributing them on the floor plan of the buildings and through the elevation of them to control the vibration in each floor level.

1- Using tuning TMDs in the context of reducing seismic vibrations of building structures based on mass ratio on two modes of vibration.

2- When combining the vibration of buildings with modal analysis can estimate the motion of the large mass on the floor and time-consuming analyses.

3- The results show the showed a significant reduction of the seismic response of the building floors in terms of relative displacements and absolute accelerations.

4- Mass ratios much higher than $40 \%$ were not recommended because they lead to an unbalanced structural solution by having a top mass that is much larger than the bottom mass

1- Investigated the dynamic behavior and the seismic effectiveness of a nonconventional TMD with a large mass ratio.

2- An optimal design method was specifically developed.

3- A non-conventional TMD with a large mass ratio outperforms is equal al. [74]

Dynamic response and optimal design of structures with large mass-ratio TMD
De Angelis et
Anh and

Design of TMD for damped linear structures using the dual criterion of the equivalent linearization method with a conventional TMD with a small mass ratio.

4- TMDs with high mass ratio are less dependent on frequency in exciting vibration than the TMDs with low mass ratio.

5- The results obtained under far-field ground motions are better than those achieved under near-fault ground motions because of the impulsive character of the latter.

1- Designing of TMD for a linear system is a classical problem and numerical methods or approximate analytical solutions for optimal parameters of TMD are proposed

2- A closed-form expression for the optimal tuning ratio of TMD attached to a damped primary structure modelled as a single-degree-of-freedom system for two cases: excitation force and ground motion.

3- The main goal of this study was improving the linearization by replacing the damped TMDs with un-damped TMDs and then using this results for access to optimal tuning ratio of TMDs.

1- Investigation the effectiveness of optimal single tuned mass damper (STMD) for wind and earthquake response control of high-rise building.

2- Optimum STMD is identified based the effective placement and tuning.

Elias and Optimum Tuned Mass Damper for Wind and Matsagar [76] Earthquake Response Control of High-Rise Building

3- Displacement, drift, acceleration and base share are reduced when $\mathrm{STMD}_{1}-\mathrm{STMD}_{5}$ were placed effectively.

4- Increasing the mass ratio of STMD help the performance criteria to be improved.

1- Analysing of mitigating effects of a TMD on dynamic responses of Taipe 101 Tower, under winds and remote seismic excitation.

2- Optimal parameters and finite element model of high-rise building equipped with TMD were studied.

Vibration Control in a 101-Storey Building Using a Tuned Mass Damper

3- The simulation results obtained were compared with the wind tunnel test data and the recorded field measurements.

4- The result shows that using of the TMD in this building was materially effective in reducing the wind-induced vibrations and TMDs were not as effective in mitigating remote seismic vibrations responses.

1- A novel passive vibration control configuration (tuned mass-damper-more inert (TMDI)) introduced to achieve enhanced performance compared to the classical TMD.

2- Analytically shown that optimally designed TMDI outperforms the classical TMD in minimizing the displacement variance of un-damped singledegree-of-freedom (SDOF) white-noise excited primary structures.

3- Optimal TMDI parameters are derived in closed-form as functions of the TMD mass and the more inert constant.

4- TMDI configuration can replace part of the TMD vibrating mass to achieve lightweight passive vibration control solutions, or improve the performance of the classical TMD for a given TMD mass 


\subsection{Active Mass Damper (AMD)}

The AMD is mighty of suppressing vibrations because of the frequently varying exterior environment since it uses actuators, sensors, and a feedback control algorithm. Therefore, the reliability of the control system should be warranted before implementation. One of the earliest approaches to the active control of vibrations in structures has been Active Tuned Mass Damper (ATMD) systems. This system is also known as an Active Mass Damper (AMD). In an ATMD system, an actuator embedded between the structure and the TMD system uses a calculated force in realtime. Kwon et al. (2017) [78] discuss the use of an ATMD system consisting of three actuators to control the windinduced motion of the 310-m Nanjing TV transmission Tower in China. For the control algorithm, they used the Linear Quadratic Gaussian (LQG), Hळ, and ongoing Sliding Mode Control (SMC) tactics, and discovered that all three made well at decreasing the vibration of the structure. Yan et al. [79] present expressions for the required control force to be applied by an ATMD system for a high-rise building with a rectangular plan subjected to vibrations because of wind loadings. Yamamoto et al. [80] present the performance results of ATMD systems mounted in four actual steel-frame high-rise buildings in Japan, ranging in height from 58.0 to $189.7 \mathrm{~m}$ (11-34 stories).

The ATMD systems for three of the buildings used existing masses, such as ice thermal storage tanks and a heliport as the controlling masses. To verify the control systems, they carried out forced vibration tests on each building before improvement, using the ATMD system itself to vibrate the building. After the ATMD system shook the building for a period of 10s, it was activated to suppress the response of the building. The authors also showed the response of the completed buildings under minor seismic events and wind loading. Their results showed that the installed ATMDs were effective at controlling the response of the buildings. Li and Liu [81] use the $\mathrm{H} 2$ control algorithm to manage the response of a two-dimensional (2D) model of a jacketed-type offshore platform in $218 \mathrm{~m}$ of water, equipped with an ATMD, and subjected to wave loadings. They found that an ATMD system performs better than a passive TMD system.

Lee and Wang [82] test the result of pitch width on the efficiency of an ATMD system, utilizing a servo motor and ball screw to control a 2D five-story frame. The ball screw is driven by the servomotor and advances the mass one pitch width per revolution through a nut. Friction between the ball screw and nut is underestimated by using metal bearing balls that are sized to fit the ball screw precisely. The authors use an optimal direct output feedback strategy where "output measurement is directly multiplied by time-invariant feedback gain and fed back to the structural system" [83] and 1940, El Centro, California earthquake as input. They found that if pitch is adjusted correctly, a 70\% reduction in peak response is possible. Conversely, if the pitch is not adjusted correctly, the ATMD system may have a harmful effect on the structure. The authors claim that this high performance, along with the minimal noise production and lack of oil leakage, makes this type of ATMD more favorable than ATMD systems driven by actuators. Pourzeynali et al. [84] had reported a combined application of genetic algorithms and fuzzy logic controller. They had shown that integration of the fuzzy logic and genetic algorithms resulted in better performance of the ATMD system in terms of response mitigation.

Yagiz and Hacioglu [85] had presented an adaptive backstepping controller with guesting for unknown systems with usage to a nine-story building model where an ATMD was mounted on the top floor as a dynamic absorber. Kahya and Araz [86] had illustrated the effectiveness of the several multiple tuned mass dampers (STMD) in bridge vibration suppression. Another TMD system was proposed using modal FRF by Debnath et al. [87] to control truss bridge vibrations. Don-Ho Yang et al modeled an Active Mass Damper (AMD) consisting of an AC servo motor, a movable mass joined to the AC servo motor by a ball-screw mechanism, and an accelerometer as a sensor for shaking measurement was discussed. The Negative Acceleration Feedback (NAF) control algorithm which uses the acceleration signal directly and produces the desired displacement for the active mass was proposed. They found that the stability situation for the NAF control is static and it can effectively increase the damping of the target natural mode without creating mutability in the low frequency scope.

Table 2. Advantages of AMD versus TMD [88]

\begin{tabular}{ll}
\hline Active Tuned Mass Damper & Passive tuned mass damper \\
\hline $\begin{array}{l}\text { I. Doesn't need to be tuned to any natural frequency of the structure } \\
\text { because they works with the measured response of the system }\end{array}$ & I. Tuned to the first natural frequency of the structure \\
$\begin{array}{l}\text { II. Characterized by having significant modal components of the critical } \\
\text { vibration modes }\end{array}$ & II. No-significant modal components of the vibration modes \\
$\begin{array}{l}\text { III. Robust and adaptive to the variations of the dynamic parameters of the } \\
\text { structure }\end{array}$ & $\begin{array}{l}\text { III. No adaptive dynamic characteristic of the structures } \\
\text { IV. More effective in controlling small vibrations of Structures }\end{array}$ \\
\hline
\end{tabular}




\subsection{Semi-Active Tuned Mass Damper (STMD)}

A semi-active tuned mass damper (STMD) with variable damping or stiffness has been proposed for structural vibration control. For this kind of damper, a passive damping device is replaced by an adjustable damping device such as a variable-orifice hydraulic damper or a device using magnetorheological fluid. Hence, only a small value of activation energy is needed to assemble the damping or stiffness of such devices, the need for a large energy store as essential by the ATMD is omitted. So, it provides an alternative to passive and active tuned mass dampers. Hrovat et al. [89] studied the interests of using an STMD for the suppression of wind-induced vibration. Assuming a specific type of wind loading, similar efficiency for the STMD and ATMD was presented. Kim et al. (2015) [5] conducted an experimental study of an STMD coupled with a three-story building model under support ground motion. The aim was to mitigate the structural response at several frequencies of vibration with a single mass damper. Using their proposed neural network control technique, they deduced that the vibration response at the first and second natural frequencies of the structure would be reduced. Hence, there is no clear research on the control performance of STMDs under harmonic stimulation, which provides very beneficial data for a wide span of control usage. Recently, Zhang et al. [90] worked on a novel semi-active tuned mass damper with tunable stiffness. The effectiveness of the classical tuned mass damper is generally confined due to the narrow bandwidth of its working frequency and the mistuning from its optimal parameters. This new semi-active TMD capable to extend its working frequency band through the stiffness tuning. The characteristic feature of this proposed tuned mass damper is that it employs a compressed tunable stiffness mechanism, which can modify its stiffness by alteration the number of active coils of springs in parallel and in series formations. This system able to achieve the real-time stiffness tuning during vibration by the performance of an appropriate control code and included the wide range of vibration frequencies.

\subsection{Technical and Economical Comparison of TMDs}

According to Table 3 the sensitivity, power, economic cost and application of three kind of TMDs have been compared and disadvantages of every systems have listed as bullet point.

Table 3. Compares the advantages and drawbacks of TMDs, AMD and Semi AMD [91]

\begin{tabular}{llll}
\hline Criteria & Tuned Mass Damper (TMD) & Active Mass Damper (AMD) & Semi-Active TMD \\
\hline Complexity & Simple mechanical devices & complex & Complex \\
Number of damped resonances & Damps only one resonance & Damps all & Damps all \\
Sensitivity to resonance frequency changes & Sensitive & Not Sensitive & Not Sensitive \\
Power & Do not require power & Requires Electrical power & Requires Battery \\
Manufacturing cost & Low & High & Medium \\
Implementation cost & High & Low & Medium \\
Mass & Proportional to target mass & Proportional to vibration energy & Proportional to stiffness \\
Implementation & Complex (tuning)/ engineering & Simple & Simple \\
\hline
\end{tabular}

\section{Numerical Modeling and Nonlinear Analysis of TMDs}

\subsection{Analytical Formulation of TMDs}

The concept of the Tuned Mass Damper dates back to the 1940s. It consists of a secondary mass with properly tuned spring and damping elements, providing a frequency-dependent device that decreases response in the primary structure. In this study we will consider the motion of the structure in only one dimension. It will, for example, not consider the motion of the building in the vertical direction, and furthermore will assume the torsional effects on the building to be negligible. According to d'Alembert principle, the differential Equations of motion for each mass from TMD takes the form [92]:

$$
\begin{aligned}
& m \ddot{x}(t)+c \dot{x}(t)+k x(t)-c_{d} \dot{x}_{d}(t)-k_{d} x_{d}(t)=-m \ddot{x}_{g}(t) \\
& m_{d} \ddot{x}_{d}(t)+C_{d} \dot{X}_{d}(t)+k_{d} x_{d}(t)+m_{d} \ddot{x}(t)=-m_{d} \ddot{x}_{g}(t)
\end{aligned}
$$

It is convenient to represent the vibrating structural system response by a state-space model in order to apply passive, semi-active or active techniques. In our case, the Equation 2, the equation of motion in which it is substituted $z_{1}=x, \mathrm{z}_{2}=\dot{\mathrm{x}}, \mathrm{z}_{3}=\mathrm{x}_{\mathrm{d}}, \mathrm{z}_{4}=\dot{\mathrm{x}}_{\mathrm{d}}$ can be written in the following state space description as: 
$\left[\begin{array}{c}\dot{z}_{1} \\ \dot{z}_{2} \\ \dot{z}_{3} \\ \dot{z}_{4}\end{array}\right]=\left[\begin{array}{cccc}0 & 1 & 0 & 0 \\ -\frac{k}{m} & -\frac{c}{m} & \frac{K_{d}}{m} & \frac{c_{d}}{m} \\ \frac{k}{m} & \frac{c}{m} & -\frac{K_{d}}{m_{d}}-\frac{K_{d}}{m} & -\frac{C_{d}}{m_{d}}-\frac{C_{d}}{m}\end{array}\right]\left[\begin{array}{c}z_{1} \\ z_{2} \\ z_{3} \\ z_{4}\end{array}\right]+\left[\begin{array}{c}0 \\ -1 \\ 0 \\ 0\end{array}\right] \ddot{x}_{g}$

Hence, the description can be modified to:

$\dot{\mathrm{z}}(\mathrm{t})=A z(t)+B \ddot{x}_{g}(t)$

$\mathrm{y}(\mathrm{t})=C z(t)+D \ddot{x}_{g}(t)$

Where: $z(t)$ is the vector of the state variables, $y(t)$ - the vector of the measurable variables $\ddot{X}_{g}(t)$ - the ground acceleration, $A$ - the system matrix, $B$ - the input matrix, $C$ - the output matrix, $D$-the connection matrix between control input, $\ddot{X}_{g}(t)$, and output, $y(t)$. Initial condition $z(0)=z 0$. Besides a time domain approach, which is a good way for evaluating the response, a transfer function analysis can provide further insight into the response of structure as the parameters of TMD are varied. The transfer function $H(s)$ is given by:

$H(s)=C(S I-A)^{-1} B+D$

Where: $I$ is identity matrix.

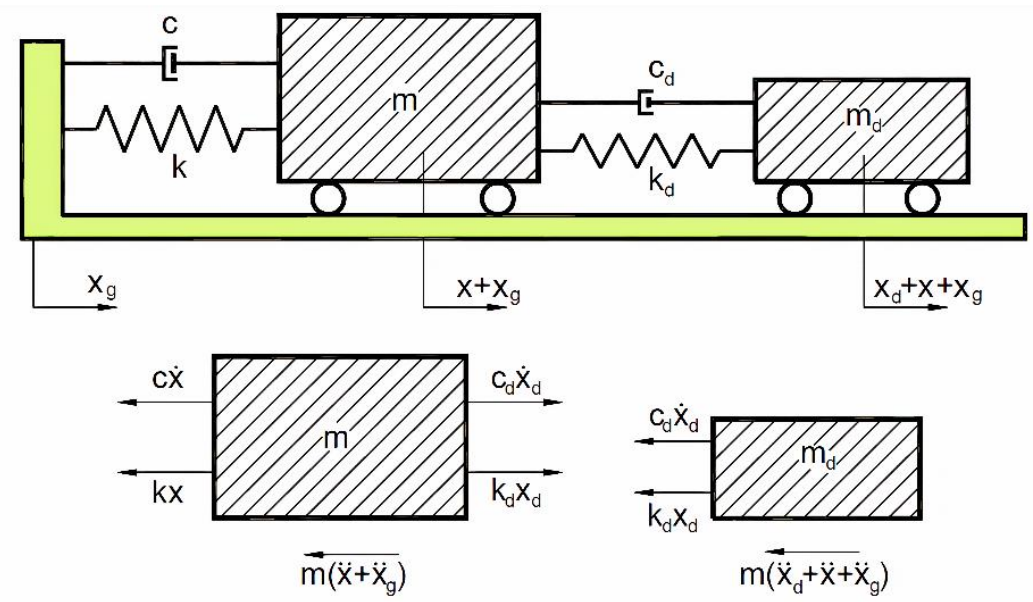

Figure 5. Mathematical model for TMD [93]

\subsection{Numerical Studies on Response of Single TMD and Multi TMD}

Some research was done on performance of a Single Tuned Mass Damper (STMD) with variable damping ratio and frequency under seismic excitations. Using an STFT relying on control algorithm, real time tuning of the damping ratio and the frequency of the STMD is performed through exploring the displacements of the STMD and the primary structure [38]. The presented results show that the STMD is effective in weaken the structural responses and outperforms the optimal passive TMD under both the regular and NF pulse-like seismic excitations. Displacement time history of the STMD can signal the accumulative energy in the STMD. A gain amplitude of the STMD declares that the STMD is absorbing energy from the primary structure and a zero damping ratio assists to make the energy flow in more quickly. Contrariwise, a decreasing amplitude of the STMD indicates that it is releasing energy to the primary structure and the damping ratio needs to be increased to a non-zero value to dissipate the energy efficiently, thereby protecting the primary structure. The non-zero damping ratio of the STMD is got based on modal analysis. Using a damping ratio twice as large as the optimal value obtained is shown effective for the STMD. Tracking the structural displacement and analysing it using STFT can prepare the frequency information of the primary structure in a timely manner. When damage occurs to the structure, this method can rapidly sense the structural frequency variation and retune the frequency of the STMD to that of the structure in real-time, thereby supporting the primary structure effectively. For structures mounted in the NF zones, the STMD proposed in the present chapter can effectively mitigate the peak response of the structures tested large response caused by the ground motions. The reduction of the STMD under pulses is related to the period of the pulse. Because the majority of the pulses have a period in the range of [0 5] s, the proposed STMD and the control algorithm is applicable for protecting the buildings in NF zones. Also, response spectra resulted from pulses in the cases of no TMD, Optimal TMD, and STMD show good compromising with that from the recorded earthquakes when $\mathrm{Tp} / \mathrm{Tn}$ is near unity. This illustrates that the pulse model and the values of the affiliated parameters is reasonable. Therefore, this provides possibility of using pulses in lieu of real ground motions to measure the behavior of the structure-STMD (or TMD) dynamic system under pulselike ground motions [94]. 

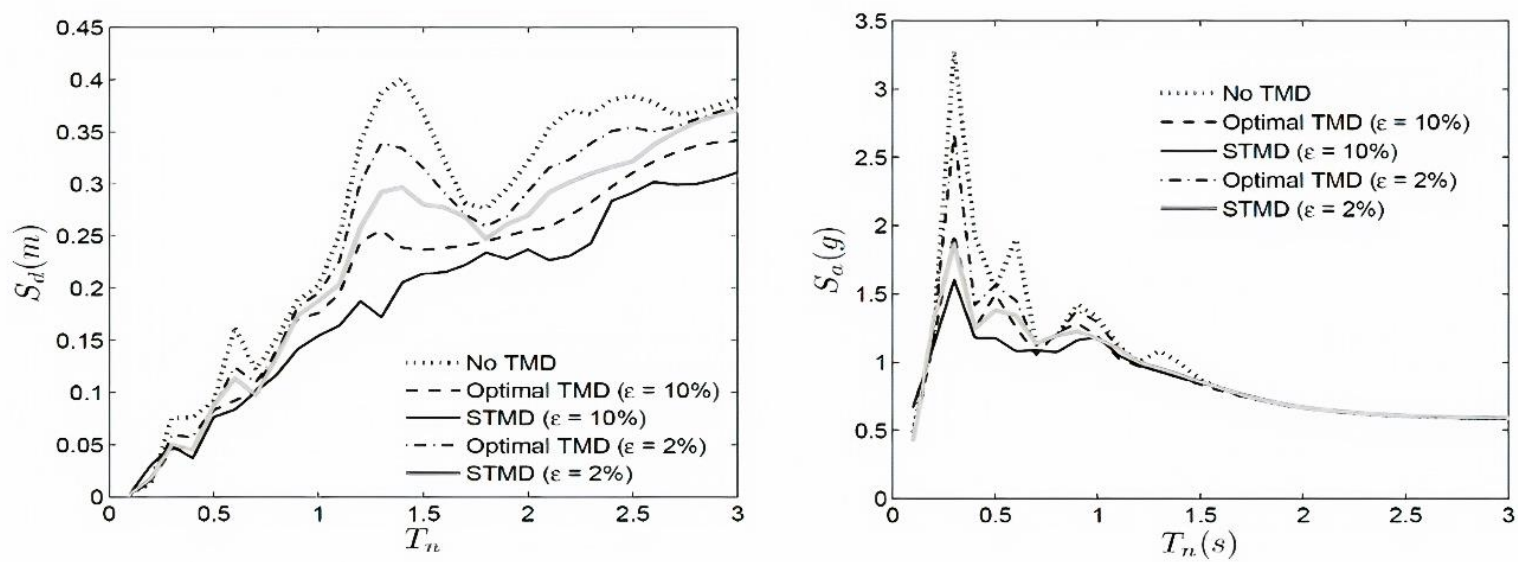

Figure 6. Response and acceleration spectra of the primary structure under Northridge (Newhall-FN) earthquake [95]

Den Hartog [96] in assessment of the optimal STMD parameters for the un-damped SDOF. Also, for the STMD mounted on a damped SDOF and for the Multi Tuned Mass Dampers (MTMDs) installed on the un-damped or damped SDOF, such collective points in the response are not observed, for which the normalized displacement intercrosses for all damping ratios. It also shows that as the mass increased, the performance of the STMD has been better for both the un-damped and damped SDOF, in such a way that the bandwidth has increased. The peak response has mitigated by increasing the damping ratio up to a certain point where optimum damping value is reached. To design the optimum STMD, the peak before the point $\mathrm{P}$ and the peak after the point $\mathrm{Q}$ must be at the same level then only the STMD could achieve maximized efficiency.

\subsection{Advances on Nonlinear Analysis of TMDs}

\subsubsection{Nonlinear Analysis of Passive TMD}

The studies showed the application of the TMDs on the structures vital remaining within the elastic limit. The structural members even in controlled structures can be predicted to exceed the elastic limit under sever seismic events, such as the 1994 Northridge and the 1995 Kobe earthquakes. Gerges and Vickery [97] developed a TMD incorporating a wire rope spring against to interchange cycles of compression and tension. The secondary mass was that of a pendulum, connected to the initial mass by a spring made of wire ropes. One of the detriment was that the recovering force of the helicoidally twisted wire ropes was non-symmetric during tension-compression cycles. Rustighi et al. [98] addressed the design and realization of a tunable beam-like TMD, consisting of two shape-memory alloy (SMA) wires heated by a flowing current. Rüdinger (2007) and Rüdinger (2006) [30, 99] investigated the effectiveness of a TMD characterized by a nonlinear viscous power law for reducing vibrations of a single- degree-offreedom system under white noise excitation. Wong [100] had proved that the hysteretic energy demand of the symmetrical buildings could be significantly mitigated by using elastic TMDs.

Koo et al. [3] accessed a remarkable improvement in the performance of a mass damper by changing the passive damping element with tunable one. Sgobba and Marano [31] investigated the optimum design of the TMDs for the seismic keeping of inelastic structures. They reported that the application of the TMD system reduces the amount of the hysteretic dissipated energy. Farshi and Assadi [101] reported that optimal nonlinear TMD is more effective in response control as contrast to the linear TMD and MTMDs. Wang [102] proposed a nonlinear TMD with the aim of suppressing machining chatter. By introducing a spring and Coulomb friction element arranged in series in a linear damped TMD, the magnitude of the frequency-response functions of the machining system can be reduced. Wu et al. [13] studied a MDOF system installed with single mass pendulum TMD considering nonlinearity. Garrido et al. (2013) [103] showed that rotational inertia double tuned mass damper (RIDTMD) was more practical than a TMD with the same mass ratio, especially at excitation frequencies near resonance. Zhang and Balendra [104] demonstrate that the initial structures achieve much better damage reduction by adopting the optimal TMD parameters. Viet and Nghi [105] proposed a non-linear single-mass two-frequency pendulum tuned mass damper (TMD) to reduce horizontal vibration. They showed that the proposed TMD has good efficiency for sever vibration. Moreover, the proposed TMD was also less sensitive to the parameter mistuning.

\subsubsection{Nonlinear Analysis of Active TMD}

$\mathrm{Li}$ and $\mathrm{Cao}$ [38] found that for the larger active tuned mass damper (ATMD1) in the hybrid active tuned mass dampers (HATMD), active-passive tuned mass dampers (APTMD), and ATMD, the negative normalized acceleration feedback gain factors (NNAFGF) scheme is remarkably better than the positive NAFGF (PNAFGF). Recently, Shu et al. [106] demonstrated a systematic way of accessing the optimal pendulum-type tuned mass damper design with considerations of uncertainties in earthquake inputs and the combined component level damages. Great efforts have 
been made towards designing adaptive TMDs (ATMDs) in achieving increased dynamic response reduction. The ATMDs are able to replace their own modal characteristics in order to follow probabilistic changes of the modal behavior. The ATMD device is expected to be capable to change either its Eigen-frequency or its damping, and some devices are required and designed to convert parameters. Various devices accede were used by several researchers; such as Varadarajan and Nagarajaiah [107] used variable stiffness tuned mass damper; Bonello et al. (2005) [108] used physics principles to offer an adaptive TMD; Gsell et al. [109] used piezo-ceramic actuators; whereas, Weber et al. [110], Weber and Maślanka [111] used magneto-rheological (MR) dampers. Rustighi et al. [98] reviewed the recent developments in adaptive TMDs. They understood that the various devices should be viewed as prototype or proof-ofconcept rather than refined devices. They reported that the researchers have demonstrated that "smart materials" can be combined into the adaptive TMDs as variable stiffness elements.

Nagarajaiah [112] introduced the concept of adaptive passive tuned mass dampers (APTMD). In addition, the new adaptive length pendulum stiffness tuned mass damper (PSTMD) was introduced. He showed that the TMD loses its performance even with just 5\% mistuning, whereas PSTMD retunes, and reduces the response effectively. In some studies, tuning methods for energy achievement were proposed considering mechanical systems and electric circuits of energy achievement Ni et al. [113]; Zuo and Cui [114]. Tang and Zuo (2011 and 2012) [115, 116] modelled two energy harvesters with the tuned mass damper systems, single-mass and dual-mass systems, and concluded that the dual-mass systems provide greater power generation with an increase of electrical damping if the energy harvester is under forced excitation, or base displacement excitation. Lately, Takeya et al. [117] showed that for effective energy harvesting, it is vital that the TMD has robustness against uncertainties in bridge vibrations and the tuning errors.

\section{Experimental Method for Analysis of TMDs}

\subsection{Distributed Mass Damper System}

One type of tuned mass damper is Distributed Mass Damper (DMD) [118]. The main objective is to provide a means to improve buildings both structurally and environmentally with a Shading Fin Mass Damper (SFMD) system. External shading fins affect the sunlight entering the building and, also, the internal temperature and lighting conditions. In the SFMD system, the fins are moveable (normal to the building face) and/or rotatable, allowing the fins positions to be adjusted for greater control and minimization of energy consumption (Figure 7). Further, the fins can act as tuned mass dampers (TMDs) that move and dissipate energy during strong structural motions such as those due to earthquakes and strong winds. The synergy of the integrated system comes not only from its individual functions but also its utilization. The proposed integrated system would perform environmental control most of the time and switch to structural control when needed, thus providing a synergistic dual-purpose system to improve building energy efficiency and enhance structural and life safety. Since shading fins are located along the height of a building, the dampers are placed on each floor instead of concentrated in a few locations like traditional TMDs. This distributed mass damper (DMD) system is more difficult for engineers to design due to the very large number of individual dampers, but can be less disruptive for architectural design because there is no massive damper at the top of the building. Massive dampers can disturb the continuation of floor plans and are problematic at the top of buildings where the space and views may be more valuable. Further, weight constrains how massive a damper can be placed at the top of the building. Since the DMD system distributes the weight throughout the building rather than concentrating it, a larger total damper weight can be implemented with the DMD system (Figure 8). The greatest challenge in designing a DMD system is the large number of damper parameters (i.e., mass, stiffness and damping coefficients for passive control, and controller for active/semi-active control); optimizing these parameters will provide an effective and robust structural control system.

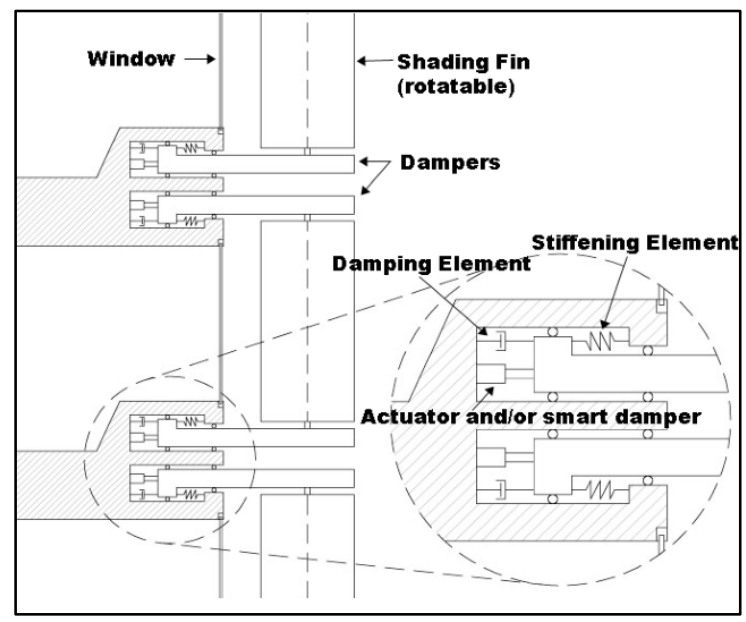

Figure 7. A shear structure with a VSDD brace control system [119] 


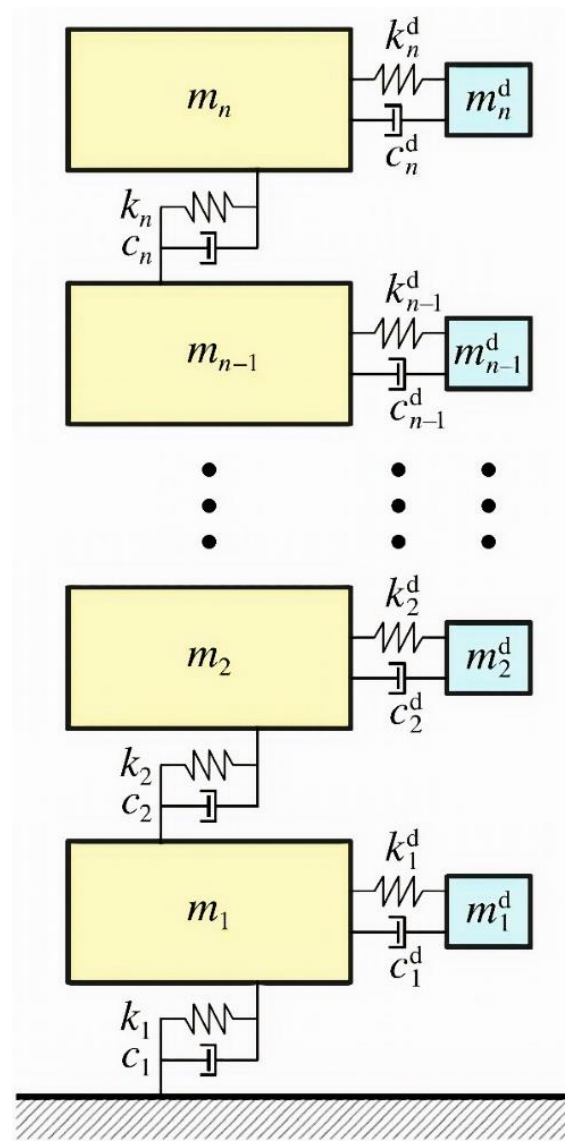

Figure 8. DMD (Distributed Mass Damper) system [120]

\subsection{Distributed Actuator Systems}

Actuation device simplifies gaining precious state data by means of arranged sensors, and also lets for contemplation intricate control formations organized by a large collection of actuators and sensors that are divided throughout the structure. Relevant works in this line contain of the design and study of complex multi-actuation systems with information constraints using advanced control design methodologies. One another technology currently being extended for use in civil structures is active vibration control (AVC) [121]. This technology can achieve remarkable diminutions in the response of a structure whilst preserving a slender structural form. AVC entails the use of one or more sensors, typically accelerometers that informant the response of the structure at key locations. These response scaling are processed in real time by a controller which generates a control voltage that drives one or more actuators. These transmit a force onto the structure in a purpose to reduce the vibrations monitored. Soto and Adeli [122] provided a computational model for active control of large structures utilizing distributed actuators against to various types of dynamic loading, such as impact, wind and earthquake loadings. Control of several equations of the open loop and closed loop systems are formulated, and a recursive performance is showed to evaluate the response of the structure. A major bottleneck in optimal active control of large structures with hundreds or thousands of members, using distributed actuators and the LQR algorithm, is the solution of the complex eigenvalue problem faced in the solution of the eventuate Riccati equation, as well as the solution of both open loop and closed loop systems of equations.

Soto and Adeli [122] presented robust and impressive parallel-vector algorithms for resolving of the Riccati equations faced in the structural control problems on apportion memory multiprocessor machines, such as the Cray YMP8/8128 supercomputer using the eigenvector come close. The algorithms are used to three large samples. It is shown that the algorithms consistently create constant conclusions for problems of different sizes while other algorithms show numerical instability for large problems. Further, it is demonstrated that the parallel processing efficiency of the parallel-vector algorithms increases with an increase in the size of the problem. One of the simplest, control rules is direct velocity feedback (DVF). This controller has the trace of presenting extra damping into the system for a broad range of modes and, in the lack of actuator dynamics, is absolutely stable. However, actuator dynamics are inevitable and have an effect on the controller, which must be taken into account via diminution of feedback gain or use of suitable compensators. Compensated acceleration feedback was developed by Brock [123] and uses phase lag and phase lead compensators on the acceleration response signal to maintain the characters of high damping of the first structural mode and high stability margins. This was made on an office floor and got reductions in the structural response of $68 \%$ and $52 \%$ for the two pacing rates utilized for excitation. Some studies have 
concentrated on the reductions that AVC would attain at a single point; generally, a single actuator sensor pair is used and located at the same location. So, this is a crucial measure of the AVC performance, it is likely that extreme vibrations are a problem over a relatively wide area not just at a single location, so it is also important to consider how far from the location of the AVC unit this reduction in response is achieved. This directly explains to the number of AVC units that would be required to successfully control a given floor area.

Hudson and Reynolds [124] introduced a compensated acceleration feedback control algorithm performed on an office floor in which a phase-lag compensator is practiced to the acceleration productions such that the properties of high damping at the basic vibration mode and high consistency margins are got, the value of time spent above a response factor was mitigated by $97 \%$ for the in-service testing. Palacios-Quiñonero et al. [125] present a controller design for the seismic preservation of tall buildings equipped with a distributed set of actuators and collocated sensors. They supposed that some of the building stories are provided with an inter-story force-actuation device and a sensing unit that can calculate the corresponding inter-story drift and inter-story velocity. They considered that the building is only partially apparatus, and the available state data is imperfect. The solution proposed in this research is based on a progressive static output-feedback H¥ approach that allows for catching controllers with defective state information by solving a two-step Linear Matrix Inequality (LMI) optimization problem.

\section{Optimization of TMD Parameters}

The effectiveness of the TMD rely on how effective the dynamic properties of the TMD are tuned to that of the structure to which it is related. Further, optimization of the parameters is necessary to increase TMD's efficiency. The following literature review presents the various optimization procedures derived for structures with TMD against to seismic excitation. Abé and Fujino [41] utilizing the perturbation solutions, formulas relevant to designing the TMD for different types of loading are gotten; they are claimed as a function of mass ratio, tuning ratio, damping ratio of the TMD and damping ratio of the structure. [126, 127] studied the effectiveness of multiple tuned mass dampers (MTMD) and optimized the parameters for an un-damped system subjected to harmonic base stimulation. It has been observed that MTMD can be more effective than a single TMD with equal mass and damping ratio and the optimum parameters of the MTMD system are obtained for different mass ratio and number of dampers. Lukkunaprasit and Wanitkorkul [128] studied the effectiveness of TMD in vibration control of buildings under medium ground shaking caused by long - distance earthquakes with frequency contents similar the 1985 Mexico City (SCT) or the 1995 Bangkok ground motion.

Elastic-perfectly plastic material behavior was presumed for the original structure, with linear TMD. The accumulated hysteretic energy dissipation affected by TMD was examined, and the ratio of hysteretic energy absorption in the structure with TMD to that without TMD is proposed to be used in conjunction with the peak displacement ratio, as a supplementary TMD performance index since it gives an indication of the accumulated damage induced in the inelastic structures. To predict the performance of TMD buildings with periods $1.7,1.8,2$, 2.15, 2.27, 2.6, 2.8 and 3 were against to the scaled Mexico and Bangkok excitations. The 2.27s period was included to match the predominant period of Bangkok earthquake excitation. The buildings were mounted with TMDs which is generalized by mass ratio of $6 \%$. It was absorbed by the authors that over the building period range of $1.8-2.8 \mathrm{~s}$, the reduction in the dissipated energy is 40 per cent or more even though there is negligible reduction in the peak displacement response and TMD deteriorated in performance with increasing hysteretic energy dissipation. Bakre and Jangid [29] showed the optimum parameters of multiple tuned mass dampers (MTMD) for repressing the response of base-excited damped main system and observed that MTMD is more effective than single tuned mass damper.

Bakre and Jangid [29], presented optimum parameters of TMD system joined to a viscously damped single degree - of - freedom main system for various combinations of excitation and response parameters. The authors have concluded that the optimum damping ratio of the TMD is not much influenced by the damping of the main system but the optimum tuning frequency of TMD is significantly affected by the damping of the main system. The first application of genetic algorithm for tuning of TMDs was performed in studies of Hadi and Arfiadi [129], Singh et al. [130], Desu et al. [131] applied particle swarm optimization technique of tuned mass dampers. Bekdaş and Nigdeli [132] used harmony search to get optimum TMD parameters. They considered maximum acceleration transfer function and first story displacement as optimization criterion under harmonic loading. A global optimization algorithm named EVOP (Evolutionary Operation) was used by Ahsan et al. [23] to optimize the design of simply supported, post-tensioned, pre stressed concrete I-girder bridge. This optimization tool was discovered to be able of position global minimum directly with high probability and without any demand of data related to gradient or subgradient of objective function. Also calculation time needed for optimization was less which is really advantageous. Bisegna and Caruso [121] proposed closed-form optimization solution for the TMD to create design formulas for maximizing the descriptive time-decay rate of the system's transient response. Islam and Ahsan [133] in studying about optimization of multiple tuned mass damper parameters proposed a global optimization algorithm named evolutionary operation (EVOP) that has been applied for optimization. Generalized equation of movement has been proposed for building frames with any number of stories accompany with any number of Tuned Mass Damper (TMD) 
at different story level against to seismic excitation. A computer program has been developed in C++ to analyze Structure-TMD system for optimization problem formulation and has been linked with EVOP. In the optimization problem optimization pattern is defined as minimization of top displacement and maximum inter-story drift. The study has been carry out to find EVOP in vibration control of structures using TMD. EVOP is found effective in minimizing structural acting with higher percentage of mitigation in sway and choice of smaller TMD parameters. Also different mixes of TMDs have been optimized for regular and irregular frames to minimize top displacement and maximum inter-story drift in two different optimization problems. It is found possible for TMDs to minimize structural response even if bottom story stiffness is less.

The performance a SMTD is improved once its parameters are optimized. Brock [134] described the procedure for determination of the optimum parameters of the TMD for an undamped structure subjected to harmonic external excitation over a broad band of excitation frequencies. Found that using an optimal passive tuned mass damper is practical in control of the structural responses under stationary Gaussian white noise shaking [135]. Jin et al. [136] studied on optimization of tuned mass damper parameters by using the artificial fish swarm algorithm. They investigate of the vibration control of floating wind turbines (FWTs) and the influence of the tuned mass damper (TMD) location on the displacements and loads of key parts of an FWT. The unknown parameters were analyzed using the LM method. The mass, damping, and stiffness of the TMD were optimized using the AFSA based on the six-DOF model. The optimization results were then compared with the results obtained using the Den Hartog method. Eventually, the wind turbine model with different TMD mounting was simulated under five load cases. The simulation results showed that the vibration decreasing effect of the TMD on wind turbines is affected by the TMD location and load case. Commonly, the vibration mitigation effect is modified when the TMD is located in the nacelle instead of the platform. The optimal vibration mitigation is gotten when TMDs are simultaneously installed in both locations. Matta [137] focused on Lifecycle cost optimization of tuned mass dampers for the seismic improvement of inelastic structures. It was considered a methodology for the LCC - optimal design of TMDs on inelastic structures, which minimizes the total seismic LCC of the composed building - TMD system. Results show that, despite their limited performance at the highest intensity levels, LCC-optimal TMDs considerably reduce the total LCC, to an extent that depends on both the building vulnerability and the TMD unit cost. They systematically introduced large mass ratios (around 10\%) and frequency and damping ratios near to their respective linearly designed optima. Simulations disclose the effectiveness of the proposed design methodology and the importance of acceptance a nonlinear model to correctly measure the cost-effectiveness of TMDs on ordinary structures in highly seismic areas. From the literature of optimization of TMD the following observations are made, 1-The effectiveness of the Tuned Mass Dampers (TMD) rely on the suitable tuning of the characteristics of TMD to that of the structure, 2-Structures with different time period respond to same earthquake in different manner, 3-The mass ratio presumed by researchers takes values much higher than applied considerations. Hence, the dynamic parameters of the TMD, i.e., the mass ratio $\mu$ (i.e., ratio of TMD mass to modal mass of the structure), frequency ratio or tuning ratio (i.e., ratio of frequency of TMD to frequency of structure) and damping ratio $\gamma$ of the TMD need to be evaluated for structures with different time period.

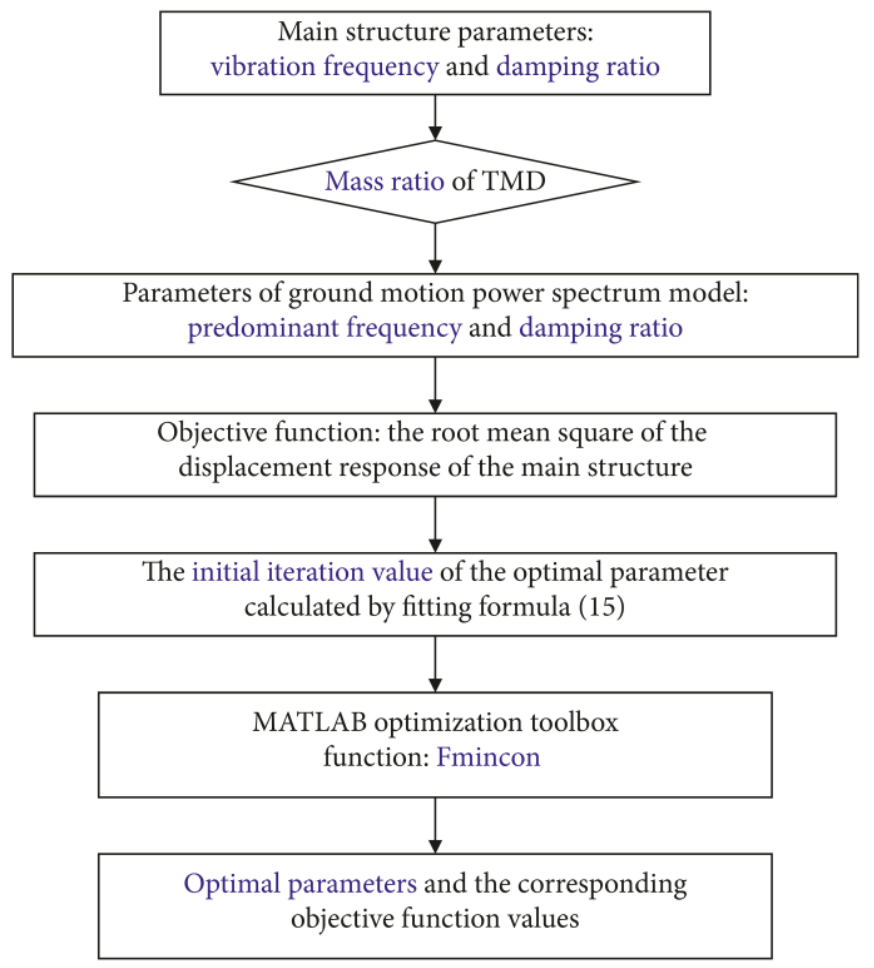

Figure 9. The numerical optimization process of TMD parameters under white noise excitations 


\section{Soil-structure Interaction and TMD Performance}

The most present researches described above were done on a rigid base and the influence of soil structure interaction (SSI) on the efficiency and control effect of structures equipped with an inter system was overlooked. It is well known that the structural response is affected by soil flexibility owing to the effects of SSI [138]. The natural period of an SSI system is longer compared to that of a fixed-base system. The damping ratios and mode shapes are also significantly modified by SSI effects, which lead to modifies in the stiffness and energy dissipation mechanism of structural systems. Samali et al. [139] did a study to discover the effectiveness of Tuned Liquid Column Dampers (TLCD) in mitigation structural vibration induced by seismic loads and contrasted with Tuned Mass Damper and TMD considering soil-structure interaction effect. They saw that natural frequencies of soil-structure system and tuning of dampers are affected by soil pliability. The effect of soil-structure interaction on the efficiency of Tuned Mass Dampers (TMD) joined to structure with pliable base under seismic stimulation was researched by Wu et al. [140]. In the study soil-structure system was done by a common frequency-independent model and a stationary random excitation was thought-out as input motion. TMD efficiency was specified in terms of root-mean-square responses. It was viewed from wide parametric study that strong soil-structure interaction considerably mitigates the seismic effectiveness of TMD. It was shown that the TMD becomes less impressive with the decrease of shear wave velocity of soil. Chouw [141] concentrated on the effect of Tuned Mass Damper on the response of frame structure during near-source ground excitations considering soil-structure interaction. It is observed from the study that the SSI and ground motion's properties may affect the effectiveness of TMD essentially. Detailed researchers are required to draw a generalized result. As can be easily recognized, most extant studies described above were performed on a rigid base, i.e., the influence of Soil structure interaction (SSI) on the performance and control effect of structures equipped with an inter system was neglected. It is well known that the structural response is affected by soil flexibility owing to the effects of SSI [142]. The natural period of an SSI system is longer compared to that of a fixed-base system. The damping ratios and mode shapes are also significantly improved by SSI effects, which lead to replaces in the stiffness and energy dissipation mechanism of structural systems [143].

SSI effects on the elastic response of SDOF and multi-degree of freedom (MDOF) systems were presented in the 1970s by scholars containing Jennings and Bielak [144]. Also, Wolf and Hall [142] have been done to analyze the impression of SSI on the seismic efficiency of structures that use different damping methods. The influence of SSI on the design of a smart hybrid system containing viscous elastic dampers and hydraulic actuators has been considered for buildings standing on soft soil. The optimized parameters of tuned mass dampers for tall buildings have been analyzed by considering SSI effects $\mathrm{Xu}$ and Kwok [143]. Chen et al. [145] investigated the effects of SSI in the seismic analyses of structures with energy dissipation devices standing on flexible soil. As mentioned above, the effects of SSI significantly influence the dynamic specifications such as the natural period and damping ratio, which are immediately related to the design of an inter system. However, the SSI effect has not still been presumed in the design of inter systems for structures standing on flexible soil. Actually, many buildings are built on soft medium where the soil-structure interaction (SSI) effect may be remarkable. It is well known that the strong SSI effect would significantly change the dynamic characteristics of structures such as natural frequencies, damping ratios and mode shapes (Wolf, 1988). Several researchers studied the SSI effect on the performance of TMD for planar buildings against to wind and earthquake excitations but led to different results. Xu and Kwok [143] checked the wind-induced motion of two super tall structures (a 76-story RC building and a $370 \mathrm{~m}$ tower) installed with TMD, taking into account the effect of soil compliancy under the footing. They asserted that soil compliancy will affect structural responses as well as the TMD effectiveness. Wu et al. [140] concentrated on the TMD seismic efficiency for structures of shallow foundations. They performed numerical investigations for a specific TMD-structure (with height of $45 \mathrm{~m}$ ) system built on soils with various shear wave velocities and found that the TMD effectiveness would decrease fast as the soil medium becomes softer. This is due to the fact that the entire soil-structure system gets more system damping for softer soil.

The efforts of Gao et al. [146] showed that the TMD is an impressive vibration control device. However, the suggested elastic half-space model without considering material damping for soil which was not suitable for seismic application was questionable and thought to be the reason that the TMD worked. Since the SSI effect is commonly difficult to be recognized accurately, the TMD detuning effect will occur because the TMD does not tune to the right frequency. To solve the problem, using MTMD is one of the promising solutions. The MTMD is a dynamic vibration control device that consists of several parallel single-degree-of-freedom (SDOF) substructures. Each substructure has its own mass, damping ratio, and natural frequency. The MTMD systems with a uniform propagation of natural frequencies were first proposed by Xu and Igusa [19] and then further investigated by Li and Liu [81]; Pansare and Jangid [147]. It has been shown that the MTMD is more effective and reliable in the decreasing of structural vibration than single TMD (STMD).

The original idea behind MTMD is to mitigate the detuning effect through appropriately distributing the tuning frequencies, which is a critical and important issue to make sure its vibration control effectiveness. The objective of researching is done by $\mathrm{Wu}$ et al. [148] claimed that investigate the influence of SSI effect on the efficiency of MTMD 
to repress the extreme vibration of torsional coupled buildings. An approach to measure the soil-irregular building interaction effect in frequency domain developed by Wu et al. [148] is occupied to compute the dynamic response for a building supported on soft soil underground-excitations. Two dimensionless parameters, stiffness ratio of soil relative to structure and slenderness ratio of structure, are explained to fully test the MTMD efficiency for various irregular buildings and soil conditions as SSI effect is significant. The optimization procedure to determine the system parameters of an MTMD system considering torsional coupled effect of the main structure is presented. To compare the vibration control effectiveness between MTMD and STMD, the response spectra for real earthquakes are displayed to guarantee the profit and reliability of MTMD. Xu and Kwok [143] evaluated the wind-induced motion of two tall structures installed with TMD, considering the effect of soil compliancy under the footing. They believed that soil compliancy will affect structural responses as well as the TMD effectiveness.

Wu et al. [140] focused on the TMD seismic performance for structures of shallow foundations. They performed numerical investigations for a specific TMD-structure (height of $45 \mathrm{~m}$ ) system built on soils with various shear wave velocities. Recently, Liu et al. [149] developed a mathematical model for time domain analysis of wind induced oscillations of a tall building with TMD considering soil effects. However, the proposed elastic half-space model without considering material damping for soil which was not satisfied for seismic application was questionable. Moreover, the past studies on TMD used for seismic applications in structures, have not considered the effects of the altered properties of the structure due to SSI, on the performance of the damper. Another device for decreasing the earth quake induced vibration of structures is multiple tuned mass damper (MTMD), which consists of different massspring systems with tuned frequencies. Wang and Lin [150] investigated the effect of MTMDs on the vibration control of irregular buildings modelled as torsional coupled structures including SSI effects. They concluded that both the SSI and eccentricity effects should be regarded for determination of optimal MTMD parameters to avoid over estimation of its effectiveness. The study of active control system for an irregular building shows that the SSI effect is significant for both squatty and slender buildings, as $\mathrm{Wu}$ et al. [148] considered. Therefore, the soil-structure interaction should be considered for the design of active control devices; especially for high-rise buildings.

Lin et al. [151] proposed a novel semi-active friction-type multiple tuned mass damper (SAF-MTMD) for vibration control of seismic structures. According to Li [152], when an asymmetric structure is built on soft soil sites, the effectiveness and robustness of the active MTMD for asymmetric structures is over computed or underestimated if the SSI effect is overlooked. Bekdaş and Nigdeli [132], Bekdaş and Nigdeli [153] represented that the dominant ground frequency and soil characteristics have important influences on the optimum parameters, effectiveness and stroke displacement of the MTMD; and the MTMD can be applied to the structures with the controlled natural frequency less than predominant earthquake frequency (Figure 10). They also did that the dominant frequency of ground motion has little smaller effect on the efficiency of the MTMD in the case of suppressing the structural acceleration response in contrast with the case of controlling the displacement response.

According to Li and Liu [154], the earthquake ground motion can be represented by a white noise for the optimum design of MTMD; where both the total mass ratio is lower than 0.02 and the total mass ratio is over 0.02 but the dominant frequency of earth quake is above the frequency of structure. Li [152] also considered the influences of various parameters in the soil-asymmetric structure interaction system on both the effectiveness and robustness of the active TMD and MTMD. Although numerous works are performed concerning SSI effects, few investigations are carried out on the time response of high-rise buildings because of earthquake excitations. In fact, the earthquake time response of tall buildings has usually been investigated employing fixed base models or single degree of freedom (SDOF) system. These analyses cannot reasonably presume the structural responses. As well as, the optimal parameters of TMD are extremely related to the soil type. Therefore, the time domain analysis of structures containing SSI effects is an advantageous process for the better understanding of earthquake fluctuations and TMD devices. Furthermore, few researching has considered and employed heuristic algorithms, while the heuristic techniques such as ant colony optimization (ACO) method, can be effectively employed for the optimized design of TMDs.

Zoka and Soheili [155] developed a mathematical model for calculating the earthquake response of a high-rise building with TMD. The model was occupied to obtain the time response of 40 story building using TMD. The ant colony optimization (ACO) method was applied on the model to get the best TMD parameters. [156] experimentally demonstrated that performance of the TMD is optimum when the natural frequency of the TMD is tuned to the predominant modal frequency of the soil-structure system. Subsequently, Jabary and Madabhushi [157] reported that tuning a TMD to the soil-structure system properties rather than fixed-base structural properties was found to double the recovery in damping and reduce the original peak response by nearly half. The parameters are evaluated with and without soil-structure inter- action (SSI) effects. The effects of different parameters such as mass, damping coefficient, spring stiffness, and natural frequency and damping ratio are evaluated. 


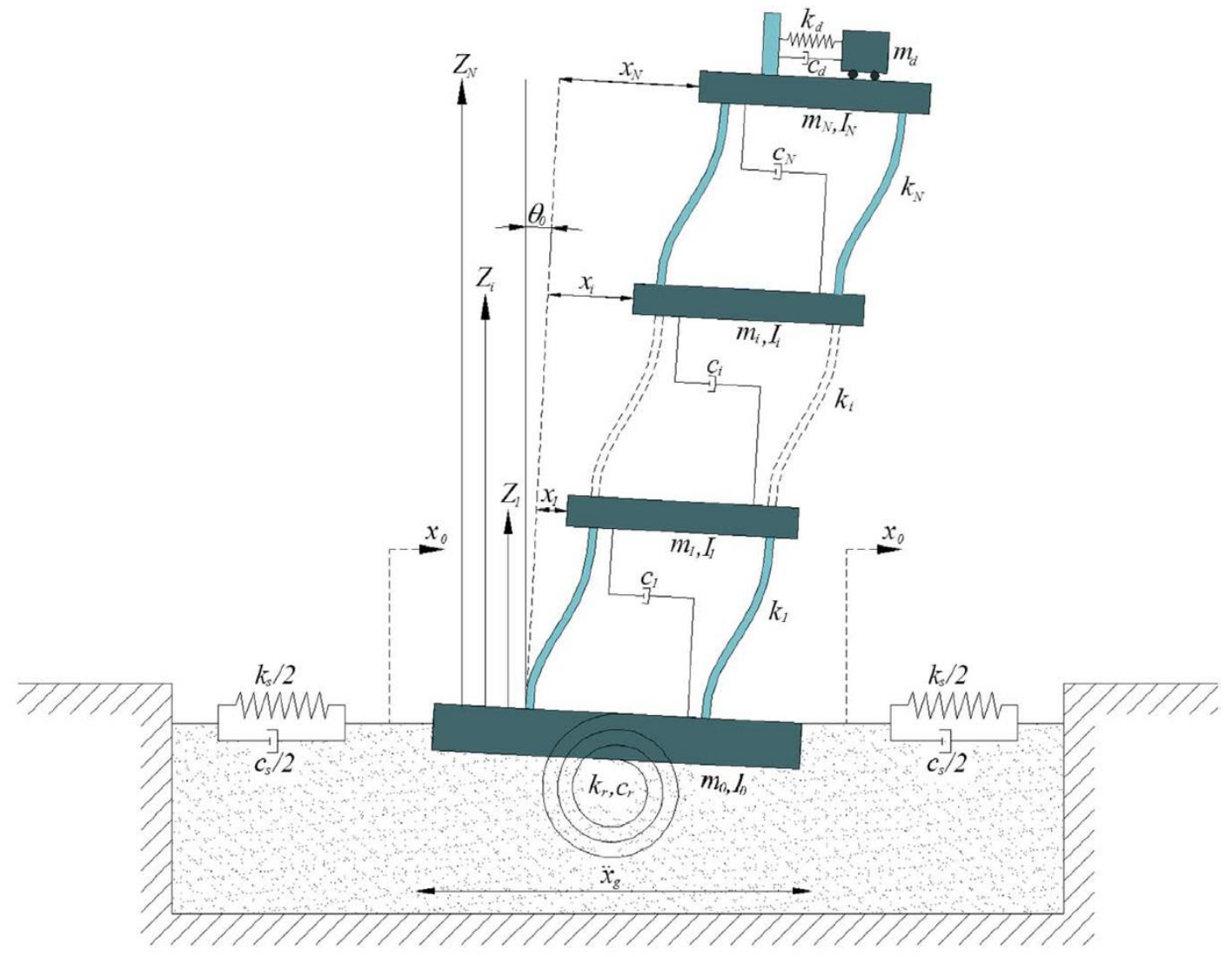

Figure 10. The TMD implemented Structure including SSI effects [153]

\section{Successful Application of TMDs in Control of Bridges}

One of the important elements for connection networks of roads and railways are bridges. Definitely, bridges have key role to play in the providing access to the towns, villages, and facilitate urban communication networks. Das and Dey [158] studied the effect of TMDs in reducing random response of simple bridges using finite element method (FEM). They reported that the performance of special arrangement of the TMD depends primarily on the nature of Eigen frequency propagation of the structure. Markiewicz [159] showed an analysis of the optimum damper impedance needs for spans, which are called dead-end spans. Some research on the utilization of the MTMDs for mitigating wind-induced vibrations of long-span bridges were taken up by researchers. Optimization of the TMD parameters for suppressing buffeting response of the long-span bridges was investigated by $\mathrm{Gu}$ and Xiang [160]. Wind-induced vibration control of long-span bridges using the MTMDs was investigated by Lin et al. [161].

Parametric study on the MTMDs for buffeting control of the Yangpu Bridge was done by Gu et al. [162]. These studies displayed that buffeting response of the bridges was mitigated because of the utilization of the TMDs. The simplest and cost-effective ways to control the vibration of a beam structure is by applying the TMD Asami and Nishihara [163]. They attached a single mass to the beam structure by viscoelastic material. Pourzeynali and Datta [164] showed the efficiency of the TMD in control of the flutter in suspension bridge deck. They reported that the mass ratio, damping ratio, tuning frequency, and number of the TMDs create maximum critical flutter wind speed of the suspension bridge. Wang et al. [165] showed that the TMD was an applicable vibration control device in reducing vertical displacements in the bridge, its absolute accelerations, end rotations, and train accelerations during resonant speeds. Chen and Cai [166] proposed a new control approach that was to weak the modal double effects, in addition to suppressing the resonant vibration with the TMDs. They discover that the new control approach converged to more impressive control performance than the conventional resonant suppression strategy when the double effects were significant and when the damping ratios in those modes of relevance were high. Hoang and Warnitchai [167] presented the usage of the MTMD system to suppress pedestrian-induced vibrations of a footbridge, and examined the sensitivity of the control effectiveness of the MTMD system against calculation of errors in the footbridge's natural frequency and enlargement of the pedestrian load. However, only the footbridge vibration generated by a single pedestrian passing was shown to illustrate the MTMDs' control effectiveness.

Chen and Kareem [168] showed the performance of the TMD in controlling the self-excited motion resulting from negative damping. They reported that the effectiveness of the TMDs is confined in controlling a hard-type flutter characterized by negative aerodynamic damping that grows rapidly with increasing wind speed beyond the on- set of 
the flutter. Chen and Huang [169] investigated the dynamic response of a single-span girder with TMDs under moving loads based on the Timoshenko beam model. Chen and Huang [169] reported that there is an upper bound of the mass ratio of the TMDs; the design will fail if the mass ratio of the TMDs is beyond this limit. They have proposed maximum of 15\% mass ratio for the up- per bound. Yang et al. [61] studied the vibrations of a clamped beam with a TMD attached to it. Chen and $\mathrm{Wu}$ [170] studied the effectiveness of the MTMDs in suppression of the wind-induced vibration in bridge structures. Hoang et al. [67] proposed transforming the deck and isolation together to act as TMD. They reported that the TMD with large mass ratio would be quite effective in reduction of the responses of the structure. They, also, found that such TMD would be huge against doubt in the parameters of the system.

\section{Conclusions and Identified Research Gaps}

It was discussed in this paper that active TMDs, compared to passive TMDs, have a significantly better performance in reducing the structural response, particularly in storey displacement. The active TMDs have even shown a good performance when the dominant frequency of excitation is close to the fundamental frequency of the structure. In addition, human comfort modes such as shear or torsional modes can be considered using active TMDs and also has a significant impact on storey shear response. All these suggest that active TMDs should be considered as the superior choice compared to passive TMDs. However, it is worth noting that while manufacturing AMDs has a relatively lower cost, it has a more operational costs mainly due to the source of energy required for activating it.

Review of the previous study on TMD's type showed that the single TMDs are utilized most in vibration control science and usually located at the top floor of the structures. Single TMDs have a good performance under wind excitation particularly for flexible structures. With regards to TMDs' efficiency is poorer during earthquake forces because not all modes of fundamental frequencies of structures were considered and it is just tuned to the dominate frequency, and this frequency is subject to uncertainties and can even alter during strong ground motions. Therefore, one future research direction can be towards tuning TMD systems to all modes of frequency.

Another important issues often neglected in the literature is the optimum design and implementation of MTMDs with purpose of sufficient damping and minimum mass ratio for torsional and shear modes of structures. While an advantage of MTMDs is that the optimum parameters can be achieved easier, due to their spatial distribution, it is clear that experimental data on their optimal design and application is very limited.

The reasons behind numerical studies are to understand how the mass ratio and damping ratio affect the normalized displacement in STMDs and MTMDs and to evaluate the efficiency of STMDs in damped SDOF. In order to do that, studies minimize the peak of acceleration response by changing the damping ratio. Unfortunately, most of these studies have been performed using linear behavior and properties, while in severe earthquakes (e.g. Kobe earthquake), the nonlinear behavior of structures play an important role. These numerical studies, then consider that a secondary mass or smart material alloy are embedded in structures to decrease the frequency response function (FRF) and hence avoid the inelastic structural behavior. However, this approach causes a lower sensitivity to mistuning. As such, it is recommended that in future studies, the nonlinearity of the damped structures needs to be considered in order to properly estimate the structural response and optimize TMDs.

The interaction between soil and structure (SSI) has been specifically highlighted in this review as it has been shown that SSI can greatly impact the performance of TMD and the control system as a whole. However, studies have largely neglected the importance of SSI, especially in soft soil where the foundation is usually complex and deep. This is even more important when special attention is given to the inherent uncertainties with soil materials, which should be carefully considered in future research in order to develop an adequate TMD optimization strategy.

In addition to the above-mentioned recommendations, further works can also be recommended to develop frequency domain analyses for AMD-controlled structures where the uncertainties in structural parameters and controlling force functions are considered. For such lines of works, the output-only modal analyses (e.g. Frequency Domain Decomposition) seem promising.

\section{Conflicts of Interest}

The authors declare no conflict of interest.

\section{References}

[1] Abburu, S.a.S., Vibration Control in High-Rise Buildings for Multi-Hazard, 2015.Master's Thesis, Civil and Environmental Engineering, LSU, Baton Rouge, Louisiana. Available online: https://digitalcommons.lsu.edu/gradschool_theses/1991. (Accessed on: 10 Apr 2020).

[2] Palacios-Quiñonero, F., J. Rubio-Massegu, J.M. Rossell, and H.R. Karimi, Recent Advances in Static Output-Feedback Controller Design with Applications to Vibration Control of Large Structures. Modeling, Identification and Control, 2014. 35(3): p. 169-190. doi:10.4173/mic.2014.3.4. 
[3] Koo, J.-H., A. Shukla, and M. Ahmadian, Dynamic Performance Analysis of Non-Linear Tuned Vibration Absorbers. Communications in Nonlinear Science and Numerical Simulation, 2008. 13(9): p. 1929-1937. doi:10.1016/j.cnsns.2007.03.020.

[4] Fisco, N. and H. Adeli, Smart Structures: Part I-Active and Semi-Active Control. Scientia Iranica, 2011. 18(3): p. $275-284$. doi:10.1016/j.scient.2011.05.034.

[5] Kim, H.-S., C. Chang, and J.-W. Kang, Control Performance Evaluation of Semi-Active Tmd Subjected to Various Types of Loads. International Journal of Steel Structures, 2015. 15(3): p. 581-594. doi:10.1007/s13296-015-9006-6.

[6] Gerges, R.R. and B.J. Vickery, Optimum Design of Pendulum-Type Tuned Mass Dampers. The Structural Design of Tall and Special Buildings, 2005. 14(4): p. 353-368. doi:10.1002/tal.273.

[7] Asai, T., Structural Control Strategies for Earthquake Response Reduction of Buildings, 2014.Ph.D. Thesis, University of Illinois at Urbana-Champaign, Civil and Environmental Engineering. Available online: http://hdl.handle.net/2142/49571. (Accessed on: 12 March 2020).

[8] Leung, A.Y., H. Zhang, C. Cheng, and Y. Lee, Particle Swarm Optimization of Tmd by Non-Stationary Base Excitation during Earthquake. Earthquake Engineering \& Structural Dynamics, 2008. 37(9): p. 1223-1246.

[9] Symans, M.D. and M.C. Constantinou, Semi-Active Control Systems for Seismic Protection of Structures: A State-of-the-Art Review. Engineering structures, 1999. 21(6): p. 469-487. doi:10.1016/S0141-0296(97)00225-3.

[10] Spencer Jr, B. and S. Nagarajaiah, State of the Art of Structural Control. Journal of structural engineering, 2003. 129(7): p. 845-856. doi:10.1061/(ASCE)0733-9445(2003)129:7(845).

[11] Eissa, M. and M. Sayed, A Comparison between Active and Passive Vibration Control of Non-Linear Simple Pendulum. Part

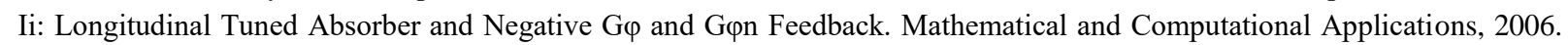
11(2): p. 151-162. doi:10.3390/mca11020151.

[12] Miah, M.S., E.N. Chatzi, V.K. Dertimanis, and F. Weber, Real-Time Experimental Validation of a Novel Semi-Active Control Scheme for Vibration Mitigation. Structural Control and Health Monitoring, 2017. 24(3): p. e1878. doi:10.1002/stc.1878.

[13] Wu, S.-T., Y.-R. Chen, and S.-S. Wang, Two-Degree-of-Freedom Rotational-Pendulum Vibration Absorbers. Journal of Sound and Vibration, 2011. 330(6): p. 1052-1064. doi:10.1016/j.jsv.2010.09.028.

[14] Desu, N.B., S. Deb, and A. Dutta, Coupled Tuned Mass Dampers for Control of Coupled Vibrations in Asymmetric Buildings. Structural Control and Health Monitoring, 2006. 13(5): p. 897-916. doi:10.1002/stc.64.

[15] Shankar, K. and T. Balendra, Building (Vibration Control). Wind Engineers, JAWE, 2001. 2001(89): p. 429-456. doi:10.5359/jawe.2001.89_429.

[16] Elias, S. and V. Matsagar, Research Developments in Vibration Control of Structures Using Passive Tuned Mass Dampers. Annual Reviews in Control, 2017. 44: p. 129-156.

[17] Cheng, F.Y., H. Jiang, and K. Lou, Smart Structures: Innovative Systems for Seismic Response Control. 2008: CRC press.

[18] Aly, A.M., Vibration Control of High-Rise Buildings for Wind: A Robust Passive and Active Tuned Mass Damper. Smart Structures and Systems, 2014. 13(3): p. 473-500. doi:10.12989/sss.2014.13.3.473.

[19] Xu, K. and T. Igusa, Dynamic Characteristics of Multiple Substructures with Closely Spaced Frequencies. Earthquake engineering \& structural dynamics, 1992. 21(12): p. 1059-1070. doi: 10.1002/eqe.4290211203.

[20] Zhou, Z., Effectiveness of Tuned Mass Dampers in Mitigating Earthquake Ground Motions in Low and Medium Rise Buildings, 2014.Master's Thesis, Civil and Environmental Engineering, Rutgers University, New Brunswick, New Jersey. doi: 10.7282/T3BK19P4.

[21] Housner, G.W., L.A. Bergman, T.K. Caughey, A.G. Chassiakos, R.O. Claus, S.F. Masri, R.E. Skelton, T. Soong, B. Spencer, and J.T. Yao, Structural Control: Past, Present, and Future. Journal of engineering mechanics, 1997. 123(9): p. 897-971. doi:10.1061/(ASCE)0733-9399(1997)123:9(897).

[22] Jia, J., Dynamic Absorber, in Modern Earthquake Engineering, J. Jia, Editor. 2017, Springer. p. 743-782. doi:10.1007/978-3642-31854-2_24.

[23] Ahsan, R., S. Rana, and S.N. Ghani, Cost Optimum Design of Posttensioned I-Girder Bridge Using Global Optimization Algorithm. Journal of Structural Engineering, 2011. 138(2): p. 273-284. doi:10.1061/(ASCE)ST.1943-541X.0000458.

[24] Yau, J.-D. and Y.-B. Yang, A Wideband Mtmd System for Reducing the Dynamic Response of Continuous Truss Bridges to Moving Train Loads. Engineering structures, 2004. 26(12): p. 1795-1807. doi:10.1016/j.engstruct.2004.06.015.

[25] Lee, C.-L., Y.-T. Chen, L.-L. Chung, and Y.-P. Wang, Optimal Design Theories and Applications of Tuned Mass Dampers. Engineering structures, 2006. 28(1): p. 43-53. doi:10.1016/j.engstruct.2005.06.023. 
[26] Li, C. and W. Qu, Evaluation of Elastically Linked Dashpot Based Active Multiple Tuned Mass Dampers for Structures under Ground Acceleration. Engineering structures, 2004. 26(14): p. 2149-2160. Doi:10.1016/j.engstruct.2004.07.019.

[27] Chang, C., Mass Dampers and Their Optimal Designs for Building Vibration Control. Engineering Structures, 1999. 21(5): p. 454-463.

[28] Lin, C.-C., J.-F. Wang, and J.-M. Ueng, Vibration Control Identification of Seismically Excited Mdof Structure-Ptmd Systems. Journal of Sound and Vibration, 2001. 240(1): p. 87-115. doi:10.1006/jsvi.2000.3188.

[29] Bakre, S. and R. Jangid, Optimum Multiple Tuned Mass Dampers for Base-Excited Damped Main System. International Journal of Structural Stability and Dynamics, 2004. 4(04): p. 527-542.

[30] Rüdinger, F., Tuned Mass Damper with Nonlinear Viscous Damping. Journal of Sound and Vibration, 2007. 300(3-5): p. 932948. doi:10.1016/j.jsv.2006.09.009.

[31] Sgobba, S. and G.C. Marano, Optimum Design of Linear Tuned Mass Dampers for Structures with Nonlinear Behaviour. Mechanical Systems and Signal Processing, 2010. 24(6): p. 1739-1755. doi:10.1016/j.ymssp.2010.01.009.

[32] Giaralis, A. and A. Taflanidis, Optimal Tuned Mass-Damper-Inerter (TMDI) Design for Seismically Excited Mdof Structures with Model Uncertainties Based on Reliability Criteria. Structural Control and Health Monitoring, 2018. 25(2): p. e2082. doi:10.1002/stc.2082.

[33] Inceo, G., S and M. Gürgöze, Bending Vibrations of Beams Coupled by Several Double Spring-Mass Systems. Journal of Sound and Vibration, 2001. 243(2): p. 370-379. doi:10.1006/jsvi.2000.3442.

[34] Rasouli, S. and M. Yahyai, Control of Response of Structures with Passive and Active Tuned Mass Dampers. The Structural Design of Tall Buildings, 2002. 11(1): p. 1-14. doi:10.1002/tal.181.

[35] Wong, K. and Y. Chee, Energy Dissipation of Tuned Mass Dampers During Earthquake Excitations. The structural design of tall and special buildings, 2004. 13(2): p. 105-121. doi:10.1002/tal.244.

[36] Krenk, S., Frequency Analysis of the Tuned Mass Damper. Journal of applied mechanics, 2005. 72(6): p. $936-942$.

[37] Hwang, J.-S., H. Kim, and J. Kim, Estimation of the Modal Mass of a Structure with a Tuned-Mass Damper Using H-Infinity Optimal Model Reduction. Engineering structures, 2006. 28(1): p. 34-42.

[38] Li, C. and B. Cao, Hybrid Active Tuned Mass Dampers for Structures under the Ground Acceleration. Structural Control and Health Monitoring, 2015. 22(4): p. 757-773. doi:10.1002/stc.1716.

[39] Xu, K. and T. Igusa, Dynamic Characteristics of Non-Classically Damped Structures. Earthquake engineering \& structural dynamics, 1991. 20(12): p. 1127-1144. Doi:10.1002/eqe.4290201204.

[40] Yamaguchi, H. and N. Harnpornchai, Fundamental Characteristics of Multiple Tuned Mass Dampers for Suppressing Harmonically Forced Oscillations. Earthquake engineering \& structural dynamics, 1993. 22(1): p. 51-62. doi: 10.1002/eqe.4290220105.

[41] Abé, M. and Y. Fujino, Efficiency and Design Formulas of Multiple Tuned Mass Dampers (Mtmd). Doboku Gakkai Ronbunshu, 1993. 1993(465): p. 97-106.

[42] Igusa, T. and K. Xu, Vibration Control Using Multiple Tuned Mass Dampers. Journal of sound and vibration, 1994. 175(4): p. 491-503.

[43] Abé, M. and Y. Fujino, Dynamic Characterization of Multiple Tuned Mass Dampers and Some Design Formulas. Earthquake engineering \& structural dynamics, 1994. 23(8): p. 813-835. doi: 10.1002/eqe.4290230802.

[44] Kareem, A. and S. Kline, Performance of Multiple Mass Dampers under Random Loading. Journal of structural engineering, 1995. 121(2): p. 348-361. doi:10.1061/(ASCE)0733-9445(1995)121:2(348).

[45] Hazra, B., A. Sadhu, A.J. Roffel, and S. Narasimhan, Hybrid Time-Frequency Blind Source Separation Towards Ambient System Identification of Structures. Computer-Aided Civil and Infrastructure Engineering, 2012. 27(5): p. 314-332. doi: 10.1111/j.1467-8667.2011.00732.x.

[46] Sakr, T.A., Vibration Control of Buildings by Using Partial Floor Loads as Multiple Tuned Mass Dampers. HBRC journal, 2017. 13(2): p. 133-144. doi:10.1016/j.hbrcj.2015.04.004.

[47] Vellar, L.S., S.P. Ontiveros-Pérez, L.F.F. Miguel, and L.F. Fadel Miguel, Robust Optimum Design of Multiple Tuned Mass Dampers for Vibration Control in Buildings Subjected to Seismic Excitation. Shock and Vibration, 2019. 2019. doi:10.1155/2019/9273714.

[48] Suresh, L. and K. Mini, Effect of Multiple Tuned Mass Dampers for Vibration Control in High-Rise Buildings. Practice Periodical on Structural Design and Construction, 2019. 24(4): p. 04019031. doi:10.1061/(ASCE)SC.1943-5576.0000453. 
[49] Pinkaew, T. and Y. Fujino, Effectiveness of Semi-Active Tuned Mass Dampers under Harmonic Excitation. Engineering Structures, 2001. 23(7): p. 850-856. doi:10.1016/S0141-0296(00)00091-2.

[50] Chen, G. and J. Wu, Optimal Placement of Multiple Tune Mass Dampers for Seismic Structures. Journal of Structural Engineering, 2001. 127(9): p. 1054-1062.

[51] Debbarma, R. and S. Hazari, Mass Distribution of Multiple Tuned Mass Dampers for Vibration Control of Structures under Earthquake Load. Int J Emerg Technol Adv Eng, 2013. 3(8): p. 198-202.

[52] Elias, S., V. Matsagar, and T.K. Datta, Effectiveness of Distributed Tuned Mass Dampers for Multi-Mode Control of Chimney under Earthquakes. Engineering Structures, 2016. 124: p. 1-16. doi:10.1016/j.engstruct.2016.06.006.

[53] Elias, S., V. Matsagar, and T.K. Datta, Distributed Tuned Mass Dampers for Multi-Mode Control of Benchmark Building under Seismic Excitations. Journal of Earthquake Eng., 2019. 23(7): p. 1137-1172. doi:10.1080/13632469.2017.1351407.

[54] Fadel Miguel, L.F., R.H. Lopez, L.F.F. Miguel, and A.J. Torii, A Novel Approach to the Optimum Design of Mtmds under Seismic Excitations. Structural Control and Health Monitoring, 2016. 23(11): p. 1290-1313. doi: 10.1002/stc.1845.

[55] Stanikzai, M.H., S. Elias, and R. Rupakhety, Seismic Response Mitigation of Base-Isolated Buildings. Applied Sciences, 2020. 10(4): p. 1230.

[56] Abburu, S.a.S., Vibration Control in High-Rise Buildings for Multi-Hazard. 2015.

[57] Kamrani-Moghaddam, B., M. Rahimian, and A.K. Ghorbani-Tanha, Performance of Tuned Mass Dampers for Response Reduction of Structures under near-Field and Far-Field Seismic Excitations, in 4th International Conference on Earthquake Engineering. 2006: Taipei, Taiwan.

[58] Pinelli, J.-P. and H. Gutierrez. Experimental Study of Tuned Mass Dampers. In Proceedings of the US National Conference on Earthquake Engineering. 2002. Earthquake Engineering Research Institute. doi:10.1088/1742-6596/744/1/012045.

[59] Lee, J., The Role of the Aerodynamic Modifications of the Shapes of Tall Buildings, 2011.Master's Thesis, Civil and Environmental Engineering, Massachusetts Institute of Technology, Massachusetts Available online: http://hdl.handle.net/1721.1/66869 (Accessed on: 9 Apr 2020).

[60] Casciati, F., G. Magonette, and F. Marazzi, Technology of Semiactive Devices and Applications in Vibration Mitigation. 2006: John Wiley \& Sons. doi:10.1002/0470022914.

[61] Yang, D.-H., J.-H. Shin, H. Lee, S.-K. Kim, and M.K. Kwak, Active Vibration Control of Structure by Active Mass Damper and Multi-Modal Negative Acceleration Feedback Control Algorithm. Journal of Sound and Vibration, 2017. 392: p. 18-30. doi:10.1016/j.jsv.2016.12.036.

[62] Sadek, F., B. Mohraz, A.W. Taylor, and R.M. Chung, A Method of Estimating the Parameters of Tuned Mass Dampers for Seismic Applications. Earthquake Engineering \& Structural Dynamics, 1997. 26(6): p. 617-635. doi:10.1002/(SICI)10969845(199706)26:6<617::AID-EQE664>3.0.CO;2-Z.

[63] Chang, C. and W. Qu, Unified Dynamic Absorber Design Formulas for Wind-Induced Vibration Control of Tall Buildings. The structural design of tall buildings, 1998. 7(2): p. 147-166. doi:10.1002/(SICI)1099-1794(199806)7:2<147::AIDTAL107>3.0.CO;2-3.

[64] Rana, R. and T. Soong, Parametric Study and Simplified Design of Tuned Mass Dampers. Engineering structures, 1998. 20(3): p. 193-204. doi:10.1016/S0141-0296(97)00078-3.

[65] Li, C. and Y. Liu, Further Characteristics for Multiple Tuned Mass Dampers. Journal of Structural Engineering, 2002. 128(10): p. 1362-1365. doi:10.1061/(ASCE)0733-9445(2002)128:10(1362).

[66] Ueng, J.M., C.C. Lin, and J.F. Wang, Practical Design Issues of Tuned Mass Dampers for Torsionally Coupled Buildings under Earthquake Loadings. The Structural Design of Tall and Special Buildings, 2008. 17(1): p. 133-165. doi:10.1002/tal.336.

[67] Hoang, N., Y. Fujino, and P. Warnitchai, Optimal Tuned Mass Damper for Seismic Applications and Practical Design Formulas. Engineering Structures, 2008. 30(3): p. 707-715. doi:10.1016/j.engstruct.2007.05.007.

[68] Ok, S.-Y., J. Song, and K.-S. Park, Development of Optimal Design Formula for Bi-Tuned Mass Dampers Using MultiObjective Optimization. Journal of Sound and Vibration, 2009. 322(1-2): p. 60-77. doi:10.1016/j.jsv.2008.11.023.

[69] Moon, K.S., Vertically Distributed Multiple Tuned Mass Dampers in Tall Buildings: Performance Analysis and Preliminary Design. The Structural Design of Tall and Special Buildings, 2010. 19(3): p. 347-366. doi:10.1002/tal.499.

[70] Lu, X. and J. Chen, Mitigation of Wind-Induced Response of Shanghai Center Tower by Tuned Mass Damper. The Structural Design of Tall and Special Buildings, 2011. 20(4): p. 435-452. 
[71] Aly, A.M., Proposed Robust Tuned Mass Damper for Response Mitigation in Buildings Exposed to Multidirectional Wind. The structural design of tall and special Buildings, 2014. 23(9): p. 664-691. doi:10.1002/tal.1068.

[72] Farghaly, A.A. and M. Salem Ahmed, Optimum Design of Tmd System for Tall Buildings. ISRN Civil Engineering, 2012. 2012. doi:10.5402/2012/716469.

[73] Moutinho, C., An Alternative Methodology for Designing Tuned Mass Dampers to Reduce Seismic Vibrations in Building Structures. Earthquake Engineering \& Structural Dynamics, 2012. 41(14): p. 2059-2073. doi:10.1002/eqe.2174.

[74] De Angelis, M., S. Perno, and A. Reggio, Dynamic Response and Optimal Design of Structures with Large Mass Ratio Tmd. Earthquake Engineering \& Structural Dynamics, 2012. 41(1): p. 41-60. doi:10.1002/eqe.1117.

[75] Anh, N. and N. Nguyen, Design of Tmd for Damped Linear Structures Using the Dual Criterion of Equivalent Linearization Method. International Journal of Mechanical Sciences, 2013. 77: p. 164-170. doi:10.1016/j.ijmecsci.2013.09.014.

[76] Elias, S. and V. Matsagar, Optimum Tuned Mass Damper for Wind and Earthquake Response Control of High-Rise Building, in Advances in Structural Engineering. 2015, Springer. p. 1475-1487. doi:10.1007/978-81-322-2193-7_113.

[77] Marian, L. and A. Giaralis, Optimal Design of a Novel Tuned Mass-Damper-Inerter (Tmdi) Passive Vibration Control Configuration for Stochastically Support-Excited Structural Systems. Probabilistic Engineering Mechanics, 2014. 38: p. 156164. doi:10.1016/j.probengmech.2014.03.007.

[78] Kwon, I.Y., H.T. Yang, P.K. Hansma, and C.J. Randall, Bioinspired Tuned Mass Damper for Mitigation of Wind-Induced Building Excitation. Journal of Structural Engineering, (2017). 143(10): p. 04017142. doi:10.1061/(ASCE)ST.1943541X.0001881.

[79] Yan, N., C.M. Wang, and T. Balendra, Optimal Damper Characteristics of Atmd for Buildings under Wind Loads. Journal of Structural Engineering, 1999. 125(12): p. 1376-1383. doi:10.1061/(ASCE)0733-9445(1999)125:12(1376).

[80] Yamamoto, M., S. Aizawa, M. Higashino, and K. Toyama, Practical Applications of Active Mass Dampers with Hydraulic Actuator. Earthquake engineering \& structural dynamics, 2001. 30(11): p. 1697-1717. doi:10.1002/eqe.88.

[81] Li, C. and Y. Liu, Optimum Multiple Tuned Mass Dampers for Structures under the Ground Acceleration Based on the Uniform Distribution of System Parameters. Earthquake engineering \& structural dynamics, 2003. 32(5): p. 671-690. doi:10.1002/eqe.128.

[82] Lee, C.L. and Y.P. Wang, Seismic Structural Control Using an Electric Servomotor Active Mass Driver System. Earthquake engineering \& structural dynamics, 2004. 33(6): p. 737-754. doi:10.1002/eqe.373.

[83] Chung, L., C. Lin, and S. Chu, Optimal Direct Output Feedback of Structural Control. Journal of Engineering Mechanics, 1993. 119(11): p. 2157-2173. doi:10.1061/(ASCE)0733-9399(1993)119:11(2157).

[84] Pourzeynali, S., S. Salimi, and H.E. Kalesar, Robust Multi-Objective Optimization Design of Tmd Control Device to Reduce Tall Building Responses against Earthquake Excitations Using Genetic Algorithms. Scientia Iranica, 2013. 20(2): p. $207-221$. doi:10.1016/j.scient.2012.11.015.

[85] Yagiz, N. and Y. Hacioglu, Backstepping Control of a Vehicle with Active Suspensions. Control Engineering Practice, 2008. 16(12): p. 1457-1467. doi:10.1016/j.conengprac.2008.04.003.

[86] Kahya, V. and O. Araz, Series Multiple Tuned Mass Dampers for Vibration Control of High-Speed Railway Bridges, in Insights and Innovations in Structural Engineering, Mechanics and Computation, A. Zingoni, Editor. 2016, CRC Press: London. doi:10.1201/9781315641645-25.

[87] Debnath, N., S. Deb, and A. Dutta, Multi-Modal Vibration Control of Truss Bridges with Tuned Mass Dampers under General Loading. Journal of Vibration and Control, 2016. 22(20): p. 4121-4140. doi:10.1177/1077546315571172.

[88] Cao, H. and Q. Li, New Control Strategies for Active Tuned Mass Damper Systems. Computers \& structures, 2004. 82(27): p. 2341-2350. doi:10.1016/j.compstruc.2004.05.010.

[89] Hrovat, D., P. Barak, and M. Rabins, Semi-Active Versus Passive or Active Tuned Mass Dampers for Structural Control. Journal of Engineering Mechanics, 1983. 109(3): p. 691-705. doi:10.1016/j.proeng.2011.07.350.

[90] Zhang, L., L. Hong, J.S. Dhupia, S. Johnson, Z. Qaiser, and Z. Zhou. A Novel Semi-Active Tuned Mass Damper with Tunable Stiffness. in 2018 IEEE/ASME International Conference on Advanced Intelligent Mechatronics (AIM). 2018. Auckland: IEEE. doi:10.1109/AIM.2018.8452301.

[91] Casciati, F., J. Rodellar, and U. Yildirim, Active and Semi-Active Control of Structures-Theory and Applications: A Review of Recent Advances. Journal of Intelligent Material Systems and Structures, 2012. 23(11): p. 1181-1195. doi:10.1177/1045389X12445029. 
[92] Mohtat, A. and E. Dehghan-Niri, Generalized Framework for Robust Design of Tuned Mass Damper Systems. Journal of Sound and Vibration, 2011. 330(5): p. 902-922. doi:10.1016/j.jsv.2010.09.007.

[93] Hayati, S., W. Song, M. Kreger, J. Lindner, and R. Berry, Disruptive Tuned Mass Damper for Response Reduction of Civil Engineering Structures, in Integrating Science, Engineering \& Policy. 2018: Los Angeles, California.

[94] Quaranta, G., F. Mollaioli, and G. Monti, Effectiveness of Design Procedures for Linear Tmd Installed on Inelastic Structures under Pulse-Like Ground Motion. Earthquakes and Structures, 2016. 10(1): p. 239-260. doi:10.12989/eas.2016.10.1.239.

[95] Sun, C., Structural Vibration Control of Nonlinear Systems Using the Smart Tuned Mass Damper (Stmd) and the Nonlinear Tuned Mass Damper (Ntmd) in Parallel, 2013.Ph.D. Thesis, Civil and Environmental Engineering, Rice University, Houston, Texas. Available online: https://hdl.handle.net/1911/77526. (Accessed on: 18 Apr 2020).

[96] Den Hartog, J.P., Mechanical Vibrations. 1985, Massachusetts: Courier Corporation.

[97] Gerges, R.R. and B.J. Vickery, Design of Tuned Mass Dampers Incorporating Wire Rope Springs: Part Ii: Simple Design Method. Engineering structures, 2005. 27(5): p. 662-674. doi:10.1016/j.engstruct.2004.12.014.

[98] Rustighi, E., M. Brennan, and B. Mace, Real-Time Control of a Shape Memory Alloy Adaptive Tuned Vibration Absorber. Smart Materials and Structures, 2005. 14(6): p. 1184. doi:10.1088/0964-1726/14/6/011.

[99] Rüdinger, F., Tuned Mass Damper with Fractional Derivative Damping. Engineering Structures, 2006. 28(13): p. 1774-1779. doi:10.1016/j.engstruct.2006.01.006.

[100] Wong, K., Seismic Energy Dissipation of Inelastic Structures with Tuned Mass Dampers. Journal of engineering mechanics, 2008. 134(2): p. 163-172. doi:10.1061/(ASCE)0733-9399(2008)134:2(163).

[101] Farshi, B. and A. Assadi, Development of a Chaotic Nonlinear Tuned Mass Damper for Optimal Vibration Response. Communications in Nonlinear Science and Numerical Simulation, 2011. 16(11): p. 4514-4523. doi:10.1016/j.cnsns.2011.02.011.

[102] Wang, M., Feasibility Study of Nonlinear Tuned Mass Damper for Machining Chatter Suppression. Journal of Sound and Vibration, 2011. 330(9): p. 1917-1930. doi:10.1016/j.jsv.2010.10.043.

[103] Garrido, H., O. Curadelli, and D. Ambrosini, Improvement of Tuned Mass Damper by Using Rotational Inertia through Tuned Viscous Mass Damper. Engineering Structures, 2013. 56: p. 2149-2153. doi:10.1016/j.engstruct.2013.08.044.

[104] Zhang, Z. and T. Balendra, Passive Control of Bilinear Hysteretic Structures by Tuned Mass Damper for Narrow Band Seismic Motions. Engineering Structures, 2013. 54: p. 103-111. doi:10.1016/j.engstruct.2013.03.044.

[105] Viet, L. and N. Nghi, On a Nonlinear Single-Mass Two-Frequency Pendulum Tuned Mass Damper to Reduce Horizontal Vibration. Engineering Structures, 2014. 81: p. 175-180. doi:10.1016/j.engstruct.2014.09.038.

[106] Shu, Z., S. Li, X. Sun, and M. He, Performance-Based Seismic Design of a Pendulum Tuned Mass Damper System. Journal of Earthquake Engineering, 2019. 23(2): p. 334-355. doi:10.1080/13632469.2017.1323042.

[107] Varadarajan, N. and S. Nagarajaiah, Wind Response Control of Building with Variable Stiffness Tuned Mass Damper Using Empirical Mode Decomposition/Hilbert Transform. Journal of engineering mechanics, 2004. 130(4): p. 451-458. doi: 10.1061/(ASCE)0733-9399(2004)130:4(451).

[108] Bonello, P., M.J. Brennan, and S.J. Elliott, Vibration Control Using an Adaptive Tuned Vibration Absorber with a Variable Curvature Stiffness Element. Smart Materials and Structures, 2005. 14(5): p. 1055. doi:10.1088/0964-1726/14/5/044.

[109] Gsell, D., G. Feltrin, and M. Motavalli, Adaptive Tuned Mass Damper Based on Pre-Stressable Leaf-Springs. Journal of Intelligent Material Systems and Structures, 2007. 18(8): p. 845-851. doi:10.1016/j.ymssp.2010.07.001.

[110] Weber, F., C. Boston, and M. Maślanka, An Adaptive Tuned Mass Damper Based on the Emulation of Positive and Negative Stiffness with an Mr Damper. Smart materials and structures, 2010. 20(1): p. 015012. doi:10.1088/0964-1726/20/1/015012.

[111] Weber, F. and M. Maślanka, Frequency and Damping Adaptation of a TMD with Controlled Mr Damper. Smart Materials and Structures, 2012. 21(5): p. 055011. doi:10.1088/0964-1726/21/5/055011.

[112] Nagarajaiah, S., Adaptive Passive, Semiactive, Smart Tuned Mass Dampers: Identification and Control Using Empirical Mode Decomposition, Hilbert Transform, and Short-Term Fourier Transform. Structural Control and Health Monitoring, 2009. 16(7-8): p. 800-841. doi:10.1002/stc.349.

[113] Ni, T., L. Zuo, and A. Kareem. Assessment of Energy Potential and Vibration Mitigation of Regenerative Tuned Mass Dampers on Wind Excited Tall Buildings. In ASME 2011 International Design Engineering Technical Conferences and Computers and Information in Engineering Conference. 2011.

[114] Zuo, L. and W. Cui, Dual-Functional Energy-Harvesting and Vibration Control: Electromagnetic Resonant Shunt Series Tuned Mass Dampers. Journal of vibration and acoustics, 2013. 135(5): p. 051018. doi:10.1115/1.4024095. 
[115] Tang, X. and L. Zuo, Enhanced Vibration Energy Harvesting Using Dual-Mass Systems. Journal of sound and vibration, 2011. 330(21): p. 5199-5209. doi:10.1016/j.jsv.2011.05.019.

[116] Tang, X. and L. Zuo, Vibration Energy Harvesting from Random Force and Motion Excitations. Smart Materials and Structures, 2012. 21(7): p. 075025. doi:10.1088/0964-1726/21/7/075025.

[117] Takeya, K., E. Sasaki, and Y. Kobayashi, Design and Parametric Study on Energy Harvesting from Bridge Vibration Using Tuned Dual-Mass Damper Systems. Journal of Sound and Vibration, 2016. 361: p. 50-65. doi:10.1016/j.jsv.2015.10.002.

[118] Fu, T.S. and E.A. Johnson, Distributed Mass Damper System for Integrating Structural and Environmental Controls in Buildings. Journal of Engineering Mechanics, 2010. 137(3): p. 205-213. doi:10.1061/(ASCE)EM.1943-7889.0000211.

[119] Fu, T.S. and E.A. Johnson. Control Strategies for a Distributed Mass Damper System. In 2009 American Control Conference. 2009. IEEE. doi:10.1109/ACC.2009.5160718.

[120] Fu, T.S. and E.A. Johnson, Active Control for a Distributed Mass Damper System. Journal of Engineering Mechanics, 2014. 140(2): p. 426-429. doi:10.1061/(ASCE)EM.1943-7889.0000650.

[121] Bisegna, P. and G. Caruso, Closed-Form Formulas for the Optimal Pole-Based Design of Tuned Mass Dampers. Journal of sound and vibration, 2012. 331(10): p. 2291-2314.

[122] Soto, M.G. and H. Adeli, Tuned Mass Dampers. Archives of Computational Methods in Engineering, 2013. 20(4): p. 419431.

[123] Brock, J.E., A Note on the Damped Vibration Absorber. Trans. ASME, Journal of Applied Mechanics, A, 1946. 28413(4): p. A-284.

[124] Hudson, M.J. and P. Reynolds, Implementation Considerations for Active Vibration Control in the Design of Floor Structures. Engineering Structures, 2012. 44: p. 334-358. doi:10.1016/j.engstruct.2012.05.034.

[125] Palacios-Quiñonero, F., J. Rubio-Massegu, J.M. Rossell, and H.R. Karimi, Recent Advances in Static Output-Feedback Controller Design with Applications to Vibration Control of Large Structures. 2014.

[126] Jangid, R., Dynamic Characteristics of Structures with Multiple Tuned Mass Dampers. Structural Engineering and Mechanics, 1995. 3(5): p. 497-509. doi:10.1002/eqe.4290230802.

[127] Jangid, R., Optimum Multiple Tuned Mass Dampers for Base-Excited Undamped System. Earthquake engineering \& structural dynamics, 1999. 28(9): p. 1041-49. doi:10.1002/(SICI)1096-9845(199909)28:9<1041::AID-EQE853>3.0.CO;2-E.

[128] Lukkunaprasit, P. and A. Wanitkorkul, Inelastic Buildings with Tuned Mass Dampers under Moderate Ground Motions from Distant Earthquakes. Earthquake engineering \& structural dynamics, 2001. 30(4): p. 537-551. doi:10.1002/eqe.22.

[129] Hadi, M.N. and Y. Arfiadi, Optimum Design of Absorber for Mdof Structures. Journal of Structural Engineering, 1998. 124(11): p. 1272-1280. doi:10.1061/(ASCE)0733-9445(1998)124:11(1272).

[130] Singh, M.P., S. Singh, and L.M. Moreschi, Tuned Mass Dampers for Response Control of Torsional Buildings. Earthquake engineering and structural dynamics, 2002. 31(4): p. 749-769. doi: 10.1002/eqe.119.

[131] Desu, N.B., S. Deb, and A. Dutta, Coupled Tuned Mass Dampers for Control of Coupled Vibrations in Asymmetric Buildings. Structural Control and Health Monitoring: The Official Journal of the International Association for Structural Control and Monitoring and of the European Association for the Control of Structures, 2006. 13(5): p. 897-916.

[132] Bekdaş, G. and S.M. Nigdeli, Estimating Optimum Parameters of Tuned Mass Dampers Using Harmony Search. Engineering Structures, 2011. 33(9): p. 2716-2723. doi:10.1016/j.engstruct.2011.05.024.

[133] Islam, B. and R. Ahsan. Optimization of Tuned Mass Damper Parameters Using Evolutionary Operation Algorithm. in 15th World Conference in Earthquake Engineering (WCEE). 2012. Lisbon, Portugal.

[134] Brock, J.E., A Note on the Damped Vibration Absorber. Trans. ASME, Journal of Applied Mechanics, A, 1946. 284.

[135] Chey, M.-H. and J.-U. Kim, Parametric Control of Structural Responses Using an Optimal Passive Tuned Mass Damper under Stationary Gaussian White Noise Excitations. Frontiers of Structural and Civil Engineering, 2012. 6(3): p. 267-280.

[136] Jin, X., S. Xie, J. He, Y. Lin, Y. Wang, and N. Wang, Optimization of Tuned Mass Damper Parameters for Floating Wind Turbines by Using the Artificial Fish Swarm Algorithm. Ocean Engineering, 2018. 167: p. 130-141. doi:10.1016/j.oceaneng.2018.08.031.

[137] Matta, E., Lifecycle Cost Optimization of Tuned Mass Dampers for the Seismic Improvement of Inelastic Structures. Earthquake Engineering \& Structural Dynamics, 2018. 47(3): p. 714-737. doi:10.1002/eqe.2987.

[138] Wolf, J. and W. Hall, Soil-Structure-Interaction Analysis in Time Domain. 1989: A Division of Simon \& Schuster. doi:10.1016/0029-5493(89)90249-5. 
[139] Samali, B., K. Kwok, G. Young, and Y. Xu. Effectiveness of Optimised Tuned Liquid Column Dampers in Controlling Vibration of Tall Buildings Subject to Strong Ground Motions. In Proc. 2nd International Conf. on Highrise Buildings. 1992.

[140] Wu, J., G. Chen, and M. Lou, Seismic Effectiveness of Tuned Mass Dampers Considering Soil-Structure Interaction. Earthquake engineering \& structural dynamics, 1999. 28(11): p. 1219-1233.

[141] Chouw, N. Behaviour of Soil-Structure System with Tuned-Mass Dampers During near-Source Earthquakes. in 13th World Conference on Earthquake Engineering, Vancouver, BC, Canada. 2004.

[142] Wolf, J. and W. Hall, Soil-Structure-Interaction Analysis in Time Domain. 1988: A Division of Simon \& Schuster.

[143] Xu, Y. and K. Kwok, Wind-Induced Response of Soil-Structure-Damper Systems. Journal of Wind Engineering and Industrial Aerodynamics, 1992. 43(1-3): p. 2057-2068.

[144] Jennings, P.C. and J. Bielak, Dynamics of Building-Soil Interaction. Bulletin of the seismological society of America, 1973. 63(1): p. 9-48.

[145] Chen, G., J. Wu, C. Chen, and M. Lou. Recent Development in Structural Control Including Soil-Structure Interaction Effect. in Smart Structures and Materials 2000: Smart Systems for Bridges, Structures, and Highways. 2000. International Society for Optics and Photonics. doi:10.1117/12.383144.

[146] Gao, H., B. Samali, and K. Kwok. Structural Vibration Control by Passive Dampers Considering Soil-Structure Interaction. in Proc. 2nd Int. Workshop on Structural Control, HJUST, Hong Kong. 1996.

[147] Pansare, A. and R. Jangid, Tuned Mass Dampers for Torsionally Coupled Systems. Wind and Structures, 2003. 6(1): p. 2340. doi:10.12989/was.2003.6.1.023.

[148] Wu, W.H., J.F. Wang, and C.C. Lin, Systematic Assessment of Irregular Building-Soil Interaction Using Efficient Modal Analysis. Earthquake engineering \& structural dynamics, 2001. 30(4): p. 573-594.

[149] Liu, M.-Y., W.-L. Chiang, J.-H. Hwang, and C.-R. Chu, Wind-Induced Vibration of High-Rise Building with Tuned Mass Damper Including Soil-Structure Interaction. Journal of Wind Engineering and Industrial Aerodynamics, 2008. 96(6-7): p. 1092-1102. doi:10.1016/j.jweia.2007.06.034.

[150] Wang, J.-F. and C.-C. Lin, Seismic Performance of Multiple Tuned Mass Dampers for Soil-Irregular Building Interaction Systems. International journal of solids and structures, 2005. 42(20): p. 5536-5554. doi:10.1016/j.ijsolstr.2005.02.042.

[151] Lin, C.-C., L.-Y. Lu, G.-L. Lin, and T.-W. Yang, Vibration Control of Seismic Structures Using Semi-Active Friction Multiple Tuned Mass Dampers. Engineering Structures, 2010. 32(10): p. 3404-3417. doi:10.1016/j.engstruct.2010.07.014.

[152] Li, C., Effectiveness of Active Multiple-Tuned Mass Dampers for Asymmetric Structures Considering Soil-Structure Interaction Effects. The Structural Design of Tall and Special Buildings, 2012. 21(8): p. 543-565.

[153] Bekdaş, G. and S.M. Nigdeli, Metaheuristic Based Optimization of Tuned Mass Dampers under Earthquake Excitation by Considering Soil-Structure Interaction. Soil Dynamics and Earthquake Engineering, 2017. 92: p. 443-461. doi: 10.1016/j.soildyn.2016.10.019.

[154] Li, C. and Y. Liu, Ground Motion Dominant Frequency Effect on the Design of Multiple Tuned Mass Dampers. Journal of earthquake engineering, 2004. 8(01): p. 89-105. doi:10.1080/13632460409350482.

[155] Zoka, H. and S. Soheili, Tmd Effects on Drift for Earthquake Oscillations of Tall Building Including Soil Effects, in 2nd National Conference on New Material and Structures. 2018: Isfahan, Iran.

[156] Jabary, R.N. and G.S. Madabhushi, Tuned Mass Damper Positioning Effects on the Seismic Response of a Soil-MdofStructure System. Journal of Earthquake Engineering, 2018. 22(2): p. 281-302. doi:10.1016/j.soildyn.2015.06.013.

[157] Jabary, R. and S. Madabhushi, Tuned Mass Damper Effects on the Response of Multi-Storied Structures Observed in Geotechnical Centrifuge Tests. Soil Dynamics and Earthquake Engineering, 2015. 77: p. 373-380. doi:10.1016/j.soildyn.2015.06.013.

[158] Das, A. and S. Dey, Effects of Tuned Mass Dampers on Random Response of Bridges. Computers \& structures, 1992. 43(4): p. 745-750. doi:10.1016/0045-7949(92)90518-5.

[159] Markiewicz, M., Optimum Dynamic Characteristics of Stockbridge Dampers for Dead-End Spans. Journal of sound and vibration, 1995. 188(2): p. 243-256. doi:10.1006/jsvi.1995.0589.

[160] Gu, M. and H. Xiang, Optimization of Tmd for Suppressing Buffeting Response of Long-Span Bridges. Journal of Wind Engineering and Industrial Aerodynamics, 1992. 42(1-3): p. 1383-1392. doi:10.1016/0167-6105(92)90146-2.

[161] Lin, Y.-Y., C.-M. Cheng, and C.-H. Lee, A Tuned Mass Damper for Suppressing the Coupled Flexural and Torsional Buffeting Response of Long-Span Bridges. Engineering structures, 2000. 22(9): p. 1195-1204. doi:10.1016/S01410296(99)00049-8. 
[162] Gu, M., S. Chen, and C. Chang, Parametric Study on Multiple Tuned Mass Dampers for Buffeting Control of Yangpu Bridge. Journal of Wind Engineering and Industrial Aerodynamics, 2001. 89(11-12): p. 987-1000. doi:10.1016/S01676105(01)00094-0.

[163] Asami, T. and O. Nishihara, H2 Optimization of the Three-Element Type Dynamic Vibration Absorbers. Journal of Vibration and Acoustics, 2002. 124(4): p. 583-592. Doi:10.1115/1.1501286.

[164] Pourzeynali, S. and T. Datta, Control of Flutter of Suspension Bridge Deck Using TMD. Wind and Structures, 2002. 5(5): p. 407-422. doi:10.12989/was.2002.5.5.407.

[165] Wang, J., C. Lin, and B. Chen, Vibration Suppression for High-Speed Railway Bridges Using Tuned Mass Dampers. International Journal of Solids and structures, 2003. 40(2): p. 465-491. doi:10.1016/S0020-7683(02)00589-9.

[166] Chen, S. and C. Cai, Coupled Vibration Control with Tuned Mass Damper for Long-Span Bridges. Journal of Sound Vibration, 2004. 278: p. 449-459. doi:10.1016/j.jsv.2003.11.056.

[167] Hoang, N. and P. Warnitchai, Design of Multiple Tuned Mass Dampers by Using a Numerical Optimizer. Earthquake engineering \& structural dynamics, 2005. 34(2): p. 125-144. doi:10.1002/eqe.413.

[168] Chen, X. and A. Kareem, Efficacy of Tuned Mass Dampers for Bridge Flutter Control. Journal of Structural Engineering, 2003. 129(10): p. 1291-1300. doi:10.1061/(ASCE)0733-9445(2003)129:10(1291).

[169] Chen, Y.-H. and Y.-H. Huang, Timoshenko Beam with Tuned Mass Dampers and Its Design Curves. Journal of Sound and Vibration, 2004. 278(4-5): p. 873-888.

[170] Chen, S. and J. Wu, Performance Enhancement of Bridge Infrastructure Systems: Long-Span Bridge, Moving Trucks and Wind with Tuned Mass Dampers. Engineering structures, 2008. 30(11): p. 3316-3324. doi:10.1016/j.engstruct.2008.04.035. 